\title{
Miro1 Regulates Activity-Driven Positioning of Mitochondria within Astrocytic Processes Apposed to Synapses to Regulate Intracellular Calcium Signaling
}

\author{
Terri-Leigh Stephen, Nathalie F. Higgs, David F. Sheehan, Sana Al Awabdh, Guillermo López-Doménech, \\ I. Lorena Arancibia-Carcamo, and Josef T. Kittler \\ Department of Neuroscience, Physiology and Pharmacology, University College London, London, WC1E 6BT, United Kingdom
}

\begin{abstract}
It is fast emerging that maintaining mitochondrial function is important for regulating astrocyte function, although the specific mechanisms that govern astrocyte mitochondrial trafficking and positioning remain poorly understood. The mitochondrial Rho-GTPase 1 protein (Miro1) regulates mitochondrial trafficking and detachment from the microtubule transport network to control activity-dependent mitochondrial positioning in neurons. However, whether Miro proteins are important for regulating signaling-dependent mitochondrial dynamics in astrocytic processes remains unclear. Using live-cell confocal microscopy of rat organotypic hippocampal slices, we find that enhancing neuronal activity induces transient mitochondrial remodeling in astrocytes, with a concomitant, transient reduction in mitochondrial trafficking, mediated by elevations in intracellular $\mathrm{Ca}^{2+}$. Stimulating neuronal activity also induced mitochondrial confinement within astrocytic processes in close proximity to synapses. Furthermore, we show that the $\mathrm{Ca}^{2+}$-sensing EF-hand domains of Mirol are important for regulating mitochondrial trafficking in astrocytes and required for activity-driven mitochondrial confinement near synapses. Additionally, activity-dependent mitochondrial positioning by Mirol reciprocally regulates the levels of intracellular $\mathrm{Ca}^{2+}$ in astrocytic processes. Thus, the regulation of intracellular $\mathrm{Ca}^{2+}$ signaling, dependent on Mirol-mediated mitochondrial positioning, could have important consequences for astrocyte $\mathrm{Ca}^{2+}$ wave propagation, gliotransmission, and ultimately neuronal function.
\end{abstract}

Key words: astrocyte; calcium; Miro; mitochondria; mobility; NMDARs

Significance Statement

Mitochondria are key cellular organelles that play important roles in providing cellular energy and buffering intracellular calcium ions. The mechanisms that control mitochondrial distribution within the processes of glial cells called astrocytes and the impact this may have on calcium signaling remains unclear. We show that activation of glutamate receptors or increased neuronal activity leads to the altered transport of mitochondria and their positioning at synapses dependent on a key mitochondrial trafficking protein called Miro1. We also show that, the control of mitochondrial movement and stopping by Miro plays an important role in regulating astrocyte calcium responses. Thus the regulation of intracellular calcium signaling, by Miro-mediated mitochondrial positioning, could have important consequences for astrocyte signaling and neuron-glial interactions.

\section{Introduction}

Astrocytes have many important and diverse roles that include maintenance of the blood-brain barrier (Abbott et al., 2006), nutri-

Received May 28, 2015; revised Oct. 21, 2015; accepted Nov. 5, 2015.

Author contributions: T.-L.S., S.A.A., and J.T.K. designed research; T.-L.S. performed research; N.F.H., D.F.S., G.L.-D., and I.L.A.-C. contributed unpublished reagents/analytic tools; T.-L.S., N.F.H., and D.F.S. analyzed data; T.-L.S. and J.T.K. wrote the paper.

This work is supported by grants from the Wellcome Trust, the Biotechnology and Biological Sciences Research Council (BBSRC), the Lister Institute for Preventive Medicine, and the European Research Council (starting grant, Fuelling Synapses); T.L.S was supported by a BBSRC PhD Studentship. We thank Victoria Vaccaro for making the Sy-GCaMP5 and all members of the Kittler laboratory for discussion and comments.

The authors declare no competing financial interests.

This article is freely available online through the J Neurosci Author Open Choice option.

Correspondence should be addressed to Josef T. Kittler, Department of Neuroscience, Physiology and Pharma- ent support of neurons (Dienel and Cruz, 2004), transmitter uptake and release (Kimelberg and Nedergaard, 2010), modulation of brain blood flow (Parri and Crunelli, 2003; Attwell et al., 2010), promotion of oligodendrocyte myelinating activity, and promoting repair of the brain in response to damage (Sofroniew, 2005). In addition, astrocytes can integrate neuronal signaling by elevating their intracellular $\mathrm{Ca}^{2+}$, which in turn triggers the release of neuroactive substances

cology, University College London, Gower Street, London, WC1E 6BT, UK. E-mail: j.kittler@ucl.ac.uk. DOI:10.1523/JNEUROSCI.2068-15.2015

Copyright $\odot 2015$ Stephen et al.

This is an Open Access article distributed under the terms of the Creative Commons Attribution License Creative Commons Attribution 4.0 International, which permits unrestricted use, distribution and reproduction in any medium provided that the original work is properly attributed. 
(glutamate, ATP and D-serine; Carmignoto, 2000; Haydon, 2001; Malarkey and Parpura, 2008). These gliotransmitters possess the ability to profoundly modulate synaptic transmission and plasticity (Araque et al., 1998; Haydon and Carmignoto, 2006; Di Castro et al., 2011; Navarrete et al., 2013; Perez-Alvarez et al., 2014; Volterra et al., 2014). Synaptically evoked astrocyte $\mathrm{Ca}^{2+}$ elevations occur in spatially restricted microdomains within their processes (Grosche et al., 1999) and represent a crucial element of astrocyte-neuron bidirectional signaling (Reyes et al., 2012).

Mitochondria are dynamic organelles that are essential for maintaining neuronal function, growth, and survival (MacAskill et al., 2010; Sheng and Cai, 2012; Birsa et al., 2013). Activitydependent positioning of mitochondria in neurons ensures that the supply of ATP and $\mathrm{Ca}^{2+}$ buffering are tightly regulated and sufficient to meet the demands of neuronal signaling (MacAskill et al., 2010; Sheng and Cai, 2012). In contrast, very little is known regarding mitochondrial dynamics in astrocytes in situ. Mitochondria are known to be present in the processes of astrocytes that ensheath synapses (Grosche et al., 1999) and their positioning in astrocytic processes could therefore be important for intracellular $\mathrm{Ca}^{2+}$ regulation, which influences $\mathrm{Ca}^{2+}$-dependent gliotransmission. However, whether and how astrocyte mitochondria are able to respond to neuronal activity and position themselves accordingly remains to be addressed. Reciprocally, how their positioning may regulate neuronal signaling is also an important unanswered question.

The trafficking of mitochondria within astrocytic processes has been shown to be dependent on microtubule and actin cytoskeletons (Kremneva et al., 2013; Jackson et al., 2014) but the motor proteins and adaptors involved are yet to be identified. Mirol is a mitochondrial Rho-GTPase protein that regulates mitochondrial trafficking and activity-driven positioning at synapses in neurons (Macaskill et al., 2009; Wang and Schwarz, 2009). Mirol contains two EF-hand $\mathrm{Ca}^{2+}$-sensing domains flanked by two GTPase domains and binds kinesin and dynein motors to couple mitochondria to the microtubule transport network. Upon $\mathrm{Ca}^{2+}$ binding to the EF-hand domains of Miro1, a conformational change induces uncoupling of mitochondria from the microtubule network, enabling docking of mitochondria at sites requiring ATP and $\mathrm{Ca}^{2+}$ buffering, which is important for maintaining ion homeostasis, and thus proper signaling in neurons (Macaskill et al., 2009; Wang and Schwarz, 2009; Birsa et al., 2013; Schwarz, 2013).

Although Mirol is well established as an important regulator of mitochondrial trafficking and positioning in neurons (Macaskill et al., 2009; Wang and Schwarz, 2009), it is unclear whether Miro proteins are important for the spatial regulation of mitochondria within astrocytic processes.

Here, we define a mechanism for neuronal activity-dependent control of mitochondrial trafficking and positioning in astrocytes. We observe that astrocytes respond to neuronal activity by elevating their intracellular $\mathrm{Ca}^{2+}$, triggering Mirol EF-handdependent mitochondrial retention near synapses, within astrocytic processes. In addition, the spatial regulation of mitochondria, dependent on the EF-hands of Miro1, appears to affect astrocytic $\mathrm{Ca}^{2+}$ signaling. Thus, Mirol-mediated mitochondrial positioning in astrocytes could have important consequences, not only for energy production and $\mathrm{Ca}^{2+}$-buffering in astrocytes, but also for $\mathrm{Ca}^{2+}$ wave propagation and gliotransmission.

\section{Materials and Methods}

Primary neuronal cultures. Hippocampal primary cultures were isolated from E18 Sprague-Dawley rats (of either sex) as described previously
(Banker and Goslin, 1998). After a 15 min incubation with 0.25\% trypsin and trituration of tissue, cells were plated onto poly-L-lysine $(500 \mathrm{mg} /$ $\mathrm{ml}$ )-coated 13 or $25 \mathrm{~mm}$ coverslips at a density of $15,000 \mathrm{cells} / \mathrm{cm}^{2}$ in attachment media [minimal essential media (MEM); Invitrogen] supplemented with $10 \%$ heat-inactivated horse serum (HRS; Invitrogen), $1 \mathrm{~mm}$ sodium pyruvate, $0.6 \%$ glucose). Media was replaced with maintenance media the following day [neurobasal medium (NB; Invitrogen), B27 supplement (Invitrogen), $2 \mathrm{~mm}$ L-glutamine, $10 \mathrm{U} / \mathrm{ml}$ penicillin, and 100 $\mu \mathrm{g} / \mathrm{ml}$ streptomycin (Pen-Strep), $0.6 \%$ glucose]. These cultured neurons were used as mixed cultures due to the presence of astrocytes. Neurons were transfected by Lipofectamine (2000) as described previously (Pathania et al., 2014).

Preparation of primary astrocytes. Primary cortical or hippocampal astrocytes cultures were prepared from E18 Sprague-Dawley rats (of either sex), as previously described (Banker and Goslin, 1998; Al Awabdh et al., 2012). Cells were maintained in DMEM with $20 \%$ heat-inactivated fetal bovine serum (Invitrogen) and 1\% Pen-Strep (10 U/ml, $100 \mu \mathrm{g} / \mathrm{ml})$. Media was changed initially the day after plating and subsequently every $5 \mathrm{~d}$ until confluency was reached (7-10 d after plating). Cells were passaged after reaching $80-90 \%$ confluency. Astrocytes were transfected by Amaxa Nucleofector, before coculturing with hippocampal neurons (E18 at similar densities), following the manufacturer's protocol using the rat astrocyte program (T-020; Smith et al., 2014). Transfected astrocytes were maintained with neurons for 3-4 d before live Optosplit imaging.

Organotypic hippocampal slice preparation. Organotypic hippocampal brain slices were prepared using the Stoppini interface method as described previously (De Simoni and Yu, 2006). Sagittal brain slices (300 $\mu \mathrm{m}$ ) were obtained from Sprague Dawley rats (of either sex), postnatal day (P)5-P7, or from transgenic mouse lines (mito-dendra2), P7-P10, using a vibratome (Leica VT1200 S) in ice-cold dissection medium [HEPES (4-(2-hydroxyethyl)-1-piperazineethanesulfonic acid) buffered EBSS (Earle's balanced salt solution)]. Slices were cultured on sterile 0.45 $\mu \mathrm{m}$ Omnipore membrane filters (Millipore; Koyama et al., 2007) and maintained for at least $7 \mathrm{~d}$ with culture medium [72\% MEM + glutamax; Invitrogen), 25\% HRS, supplemented with $20 \mathrm{~mm}$ HEPES, $36 \mathrm{~mm}$ glucose, and 1.06\% Pen-Strep (10 U/ml, $100 \mu \mathrm{g} / \mathrm{ml})$ with $16 \%$ Nystatin $(10$, $000 \mathrm{U} / \mathrm{ml}$ )] before biolistic transfection or transduction with viral plasmids and imaged $3 \mathrm{~d}$ later. Imaging was confined to the CA1 and CA3 where possible. For mouse slices, the culture medium was supplemented with $5 \mathrm{~mm}$ Tris solution. Media was changed the day after slicing and every $3 \mathrm{~d}$ after that.

\section{Antibodies and drugs}

A rabbit Miro antibody (Atlas, HPA010687) was used to label Mirol and Miro2 (1:500) in organotypic slices and in Western blots (1:1000). The vesicular glutamate transporter 1 (VGLUT1) guinea pig antibody (Synaptic Systems, 135-304) was used to label synapses (1:500 for slices and 1:1000 for cultures). A NeuN mouse antibody (Millipore Bioscience Research Reagents, MAB377) was used to label neuronal cell bodies (1:500). The GFAP rabbit antibody (DAKO, Z0334) was used to label astrocytes (1:500). A MAP2 mouse antibody (Sigma-Aldrich, M9942) was used to label dendrites (1:500). A rabbit Actin (Sigma-Aldrich, A2066) antibody was used at 1:1000 for Western blotting experiments. Secondary antibodies AlexaFluor 405 mouse and AlexaFluor 633 rabbit were purchased from Invitrogen and used at 1:500. The HRP-conjugated secondary rabbit antibody was purchased from Rockland (611-1102) and used at 1:1000.

TTX (tetrodotoxin; used at $1 \mu \mathrm{M})$, D-APV [( $2 R)$-amino-5-phosphonopentanoate; used at $50 \mu \mathrm{M}$ ], MK-801 (Dizoclipine; used at $100 \mu \mathrm{M}$ ), and MCPG ( $\alpha$-methyl-4-carboxyphenylglycine; used at $1 \mathrm{~mm}$ ) were purchased from Tocris Bioscience. 4-AP (4-aminopyridine; used at $100 \mu \mathrm{M})$, glycine (used at $1 \mu \mathrm{M}$ ), glutamate (L-glutamatic acid; used at $100 \mu \mathrm{M}$ ), NBQX (2,3-dihydroxy-6-nitro-7-sulfamoyl-benzo[f] quinoxaline-2,3dione; used at $50 \mu \mathrm{M}$ ), and EGTA (used at $100 \mu \mathrm{M}$ ) were purchased from Sigma-Aldrich.

Plasmid constructs. mtdsRed2 was from Clontech (PT3633-5). Miro ${ }^{\mathrm{WT}}$-ires-mtdsRed2 and Miro ${ }^{\mathrm{DEF}}$-ires-mtdsRed 2 constructs were made in house by cloning Mirol constructs into a bicistronic ires vector containing mtdsRed2. pGFAP-MyrGFP (GFAP-driven GFP) was from Addgene (no. 22672; Nam and Benezra, 2009). pCMV-GCaMP6s was 
also from Addgene (no. 40753; Chen et al., 2013). Presynaptically targeted GCaMP5 (Sy-GCaMP5) was cloned using SyGCaMP2 (no. 26124; Dreosti et al., 2009) from Addgene as a target vector and inserting GCaMP5G from Addgene (no. 31788; Akerboom et al., 2012) via the restriction sites SalI and NotI.

\section{Viral constructs}

Adenovirus (AV-5)-mtdsRed2-ires-EGFP. An adenovirus (AV)-encoding mtdsred2-ires-EGFP was generated in the laboratory using Gateway Vector Technology (Invitrogen). Initially the mitochondrially targeted red fluorescent protein, mtdsred2, an internal ribosome entry site (ires/ir) followed by enhanced green fluorescent protein (EGFP), driven by a CAG promoter, a polyadenylation tail ( $\mathrm{pAd}$ ) and a Woodchuck hepatitis promoter regulatory element to enhance expression, $5^{\prime}$ to the stop codon, were cloned into the pENTR4A dual expression vector. An LR clonase reaction, catalyzed by the Clonase II enzyme (Invitrogen) allowed the successful transfer of the sequence of interest into the adenovirus vector, pAd/PL-DEST (Invitrogen). Viral packaging, amplification and purification were performed in the laboratory and a viral stock of $2.6 \times 10^{16} \mathrm{PFU}$ (plaque forming units) was generated.

Adeno-associated virus (AAV-2)-mtdsRed2-ires-EGFP. To generate the adeno-associated virus (AAV) that would allow for a sparse labeling of neurons with transgenes of interest a modified AAV backbone was created. The AAV backbone was modified to include site-specific recombination sites flanking a chloramphenicol resistance-ccdB coding sequence (cloned from the pAd/PL-DEST vector). Site-specific recombination (with Clonase II enzyme) of the pENTR vector and the modified AAV vector results in the transfer of sequence of interest into the AAV vector. The AAV-mtdsRed2-ires-EGFP construct was subsequently sent to Penn Vector Core (University of Pennsylvania) for manufacture.

Adenovirus ( $A V-5)$-CRE. An adenovirus encoding CRE was purchased from Penn Vector and used to induce CRE-loxP recombination and consequently, expression of mito-dendra2 in slices from the mouse transgenic line floxed-stop-mito-dendra2 (Pham et al., 2012).

\section{Transfection}

Viral transduction. Slices were infected by adding $20 \mu \mathrm{l}$ of virus diluted in slicing media (1:1000) for $3 \mathrm{~d}$ before imaging or fixing. Virus titers were as follows: AV-CRE, $1 \times 10^{14} \mathrm{PFU}$; AV-mtdsRed2-ires-EGFP, $2.6 \times$ $10^{16}$ PFU; AAV-mtdsRed2-ires-EGFP, $2.4 \times 10^{12}$ PFU.

Biolistic slice transfection. Organotypic slice cultures (rat P7) were biolistically transfected at 7 DIV using a Helios gene gun (Bio-Rad; Woods and Zito, 2008). This involved coating small $(0.6 \mu \mathrm{m})$ gold particles, which preferentially transfect astrocytes in situ (Benediktsson et al., 2005) with up to $40 \mu \mathrm{g}$ of DNA (a maximum of $20 \mu \mathrm{g}$ for each construct if more than one was used). This allowed sparse transfection of astrocytes in organotypic slices. Postimaging immunohistochemistry staining with GFAP and MAP2 was used to confirm cell-type specificity. The tripleexpression system involved coating bullets with Mirol ${ }^{\mathrm{WT} / \Delta \mathrm{EF}}$-iresmtdsRed2 and GFAP promoter driven GFP DNA or GCaMP6s DNA.

Treatment of organotypic hippocampal slice cultures for fixed imaging. Slices were treated 3-4 d postinfection. Slices were transferred to a 24 -well plate containing organotypic media supplemented with the relevant drugs and incubated for the appropriate amount of time at $37^{\circ} \mathrm{C}$. The slices were washed with organotypic media before fixing with $4 \%$ PFA [ $4 \%$ paraformaldehyde, $4 \%$ sucrose, 50\% PBS (137 mM NaCl, $2.7 \mathrm{~mm}$ KCL, $10 \mathrm{~mm}$ $\mathrm{Na}_{2} \mathrm{HPO}_{4}, 2 \mathrm{~mm} \mathrm{KH}_{2} \mathrm{PO}_{4}, \mathrm{pH}$ 7)]. For experiments using EBSS $+\mathrm{Ca}^{2+}$ the composition was as follows: $\mathrm{EBSS}$ (no $\mathrm{Ca}^{2+}$, Invitrogen) supplemented with $1.8 \mathrm{mM} \mathrm{CaCl}_{2}, 1 \mathrm{~mm} \mathrm{MgCl}_{2}$, and $5.56 \mathrm{~mm}$ D-glucose. For experiments with $0\left[\mathrm{Ca}^{2+}\right]_{\mathrm{e}}$, EBSS (no Ca ${ }^{2+}$, Invitrogen) was supplemented with1 $\mathrm{mm} \mathrm{MgCl}_{2}$, $5.56 \mathrm{~mm}$ D-glucose, and $100 \mu \mathrm{m}$ EGTA.

Live confocal imaging. Hippocampal slices or cultured astrocytes were imaged live using an upright Zeiss LSM700 confocal microscope with a $63 \times$ (1 NA) water objective. Slices or coverslips were transferred to a recording chamber perfused with aCSF imaging media $(125 \mathrm{~mm} \mathrm{NaCl}, 10 \mathrm{~mm}$ D-glucose, $10 \mathrm{~mm}$ HEPES, $5 \mathrm{~mm} \mathrm{KCl}, 2 \mathrm{~mm} \mathrm{CaCl}, 1 \mathrm{~mm} \mathrm{MgCl}$, pH 7.4) at a rate of $5 \mathrm{ml} / \mathrm{min}$, heated to $35-37^{\circ} \mathrm{C}$. Perfusion was supplemented with drug combinations (indicated in the legend of Fig. 2) for $5 \mathrm{~min}$, slices were then washed for $5 \mathrm{~min}$. Images were acquired at 1 frame every $5 \mathrm{~s}$, except for imaging GCaMP6s, where images were acquired every $2 \mathrm{~s}$. Excitation was achieved via diode lasers at wavelengths of 488 and $555 \mathrm{~nm}$.

Live Optosplit imaging. An inverted Zeiss Axiovert 200 microscope (63×, 1.4 NA, oil objective), attached to an Evolve (EMCCD) camera (Photometrics), fitted with an image splitter (Optosplit II, Cairn Research), allowed simultaneous acquisition of images at two separate emission wavelengths. Images were acquired with $30 \mathrm{~ms}$ exposure at 1 frame every $2 \mathrm{~s}$ using Micro-manager software (Edelstein et al., 2010). Excitation was achieved through a D470/40× filter (Chroma) and emission was split using a 565DCXR dichroic beam-splitter (Chroma), subsequently collecting with HQ522/40M and HQ607/75M (Cairn Research) filters for SyGCaMP5 and mtdsRed2, respectively. A Grass S9 stimulator and a stimulation bath (Warner Instruments) allowed field stimulation ( $20 \mathrm{~Hz}$ for $20 \mathrm{~s}$ ) of $25 \mathrm{~mm}$ coverslip-plated neuron-astrocyte enriched cultures.

Immunofluorescence. For immunofluorescence, cells on coverslips and organotypic slices were fixed with $4 \%$ PFA for $10 \mathrm{~min}$. Cells were washed with PBS and subsequently permeabilized with $0.2 \%$ Triton- 100 in blocking solution (10\% HRS, $0.5 \%$ bovine serum albumin in PBS) at room temperature for $10 \mathrm{~min}$. Coverslips were incubated with primary antibody, diluted in blocking solution, for $1 \mathrm{~h}$ at room temperature. Following washing with PBS, the cells were incubated for another hour with secondary antibodies. The coverslips were washed several times and then mounted on microscope slides using ProLong Gold antifade reagent (Invitrogen). Organotypic slices were blocked with blocking solution for $4-6 \mathrm{~h}$ before incubation with primary antibody overnight at $4^{\circ} \mathrm{C}$. The following day the slices were washed (with PBS) and blocked for a further $4-6 \mathrm{~h}$ before being incubated with secondary antibodies (diluted in block solution, $0.4 \%$ Triton) overnight at $4^{\circ} \mathrm{C}$. The slices were mounted on microscope slides with Vectorshield hard-set mounting medium (Vector Laboratories) and then covered with $18 \mathrm{~mm}$ coverslips. Images of fixed cultures or slices were taken on a Zeiss LSM700 confocal using a $63 \times$ oil objective (1.4 NA).

Image processing. Mitochondrial morphology was analyzed by manually calculating mitochondria length in a maximum intensity projection of regions of interest, using ImageJ. This was achieved by tracing the longest line along each mitochondrion and establishing the output length in micrometers.

Mitochondrial mobility was assessed by counting the number of mitochondria moving as a percentage of the total number of mitochondria (mitochondria in the soma were omitted). Mitochondria in a field of view were manually classed as moving if they moved $>2 \mu \mathrm{m}$ throughout the movie. Oscillating mitochondria were identified as moving back and forth no more than $2 \mu \mathrm{m}$ from their initial position. Immobile mitochondria were manually identified as not moving and not oscillating. For pharmacological slice treatments the resultant percentage of moving mitochondria was assessed in the 5 min period post-treatment and compared with the respective $5 \mathrm{~min}$ period before treatment (with the exception of TTX and $0 \mathrm{Ca}^{2+}$ experiments, which were compared with the average of all pretreatments).

Kymographs were created as described previously (Macaskill et al., 2009; Muir et al., 2010; Twelvetrees et al., 2010). Processes were straightened using the Straighten macro in ImageJ and kymographs created using the Multiple Kymograph plugin (ImageJ; with a line width of 1). Resultant kymographs show the process along the $x$-axis and time projected down the $y$-axis. Height of the kymographs is $15 \mathrm{~min}$, unless otherwise stated. Immobile mitochondria can be identified as straight lines, diagonal lines represent moving mitochondria, and oscillating mitochondria can be seen as spatially confined zigzag lines.

The average velocities $(\mu \mathrm{m} / \mathrm{s})$ of moving mitochondria were quantified using the ImageJ Manual Tracking plugin. Because mobility was usually accompanied by brief pauses, along with changes in direction, mitochondria that paused for $>5 \mathrm{~s}$ or moved $<2 \mu \mathrm{m}$ throughout the movie were omitted. For pharmacological slice treatments mitochondrial velocity was assessed in the 5 min period post-treatment and compared with each respective 5 min period immediately before treatment (with the exception of TTX and $0 \mathrm{Ca}^{2+}$ experiments, which were compared with the average of all pretreatments). 
For synaptic recruitment experiments, the positioning of mitochondria, labeled with mtdsRed2, along astrocytic processes were assessed in relation to VGLUT1-labeled presynaptic vesicles (used to label synapses). Images were manually thresholded and using the ImageJ plugin JACoP (Objects based methods of colocalization; Bolte and Cordelières, 2006), the minimum distance from the center of mass of each mitochondrion to the center of mass of each VGLUT1 puncta in the proximal axon was established. From the JACoP data the number of synapses and mitochondria were also calculated and normalized to the length of each process (per $\mu \mathrm{m}$ ).

Monte Carlo simulations. The spatial positioning of mitochondria in relation to synapses was investigated using Monte Carlo simulations. The astrocyte was considered a $30 \mu \mathrm{m}$ straight line ( $x$-axis) upon which a given number of mitochondria were randomly distributed. The synapses were also initially randomly distributed along the $30 \mu \mathrm{m}$ line. As synapse position could also vary along an axis perpendicular to the $30 \mu \mathrm{m}$ straight line, synapse coordinates included a $y$-axis component. Mitochondrial length and synapse length were set at $2 \mu \mathrm{m}$ and $0.4 \mu \mathrm{m}$, respectively. The number of mitochondria and synapses was generated from the respective Gaussian distributions of the experimental data. Finally, the synaptic perpendicular distance ( $y$-component) was determined from inverse transform sampling of the corresponding experimental data. For each simulation, the minimum distance to the nearest synapse was calculated for each mitochondrion. One thousand independent simulations were performed and the mean minimum distance over all of the simulations is presented.

Mitochondrial fusion rate. In each experiment, an $80 \times 80 \mu \mathrm{m}$ region in the distal processes was switched with $405 \mathrm{~nm}$ confocal laser light $(200$ iterations $\sim 0.6 \mathrm{~mW}$ ). This switched the green mito-dendra2-labeled mitochondria to red. To calculate the mitochondrial fusion rate, an automated approach was used to measure colocalization (Pearson's $R$ value, JACoP, ImageJ) of the manually thresholded red and green mitodendra2 channels. This represents overlap between the switched red mito-dendra2 signal and green mito-dendra2 signal redistributing into the switched area against time. Results were normalized to the $R$ value of the preswitched signal (results are therefore Rvalue/Rvalue $e_{-2}$ ) in each experiment. A normalized $R$ value closer to 1 represents little change from the switched value and little fusion. A normalized $R$ value $>1$ represents a change from the switched value and reflects an increase in fusion.

Western blotting. For Western blotting $30 \mu \mathrm{g}$ of lysates from pure astrocyte cultures were loaded onto $10 \%$ acrylamide gels and following SDS-PAGE transferred to nitrocellulose membranes (GE Healthcare Bio-Science) using the Novex system (Invitrogen). Membranes were blocked in 4\% milk in PBS supplemented with 0.1\% Tween 20 (PBS-T) for $1 \mathrm{~h}$ and incubated with primary antibody [Mirol rabbit Atlas antibody (1:1000) and Actin rabbit Sigma-Aldrich antibody (1:1000)] overnight at $4^{\circ} \mathrm{C}$. Following several washes with $4 \%$ milk in PBS-T membranes were incubated with HRP-conjugated secondary antibodies (Rockland) for $1 \mathrm{~h}$ at room temperature. Membranes were developed using ECL-Plus reagent (GE Healthcare Bio-Science) and acquired in a chemiluminescence imager coupled to a CCD camera (ImageQuant LAS 4000 GE Healthcare).

Statistical analysis. All data were obtained using cells from at least three different animals/preparations. Results are presented as mean \pm SEM. Statistical analysis was performed using Student's unpaired, two-tailed, two-sample $t$ test (homoscedastic variance) in Excel. One-sample $t$ tests were performed in Mathematica. Statistical significance is indicated by the following: ${ }^{\star} p<0.05,{ }^{* *} p<0.01,{ }^{* *} p<0.001$. Significance was corrected for multiple comparisons, where applicable, using either Bonferroni or Dunn's post hoc tests and $n$ values are indicated in the figure legends.

\section{Results}

Basal mitochondrial trafficking dynamics differ in astrocytes compared with neurons in situ

Initially we characterized the nature of mitochondrial trafficking in astrocytic processes compared with neuronal dendrites, under basal conditions. Mitochondria in rat hippocampal slices were labeled using a viral approach and imaged using live confocal microscopy. A serotype-5 AV was used to transduce astrocytes with mitochondrially targeted dsRed2 (mtdsRed2) and EGFP (Fig. 1A). Serotype 5 human adenoviruses preferentially transduce astrocytes (Duale et al., 2005), due to the high levels of coxsackievirus and adenovirus receptor expression in astrocytes, to which the AV binds. Neurons were transduced with a serotype-2 AAV, also encoding mtdsRed2 and EGFP (Fig. 1B). AAVs, in particular serotype-2, preferentially transduce neurons via their selective binding to integrin receptors more highly expressed by neurons (Bartlett et al., 1998). The majority of the AV-transduced cells colocalized with GFAP, whereas the majority of the cells transduced with the AAV colocalized with MAP2, confirming correct viral tropism (Fig. $1 A, B$ ). Mitochondria were distributed throughout the processes of astrocytes, accumulating in the soma and extending out into the most distal regions of the cell, where they were also observed in the finer processes (with a width of $\sim 300 \mathrm{~nm}$; Fig. 1A). Under basal conditions, significantly more mitochondria were moving in neuronal processes $(53.6 \pm 1.3 \%)$ compared with the processes of astrocytes $(31.3 \pm$ $3.2 \%$; Fig. $1 C ; p=0.0007)$. In astrocytic processes, a significant percentage of mitochondria were also found to exhibit oscillating (back and forth) movements $(36.8 \pm 5.8 \%)$, in contrast to neurons, where this type of movement was almost absent $(2.5 \pm$ $0.4 \%$; Fig. $1 C ; p=0.002$ ). The function of these oscillating movements is not clear. Neuronal mitochondria moved significantly faster $(0.3 \pm 0.02 \mu \mathrm{m} / \mathrm{s})$ than astrocytic mitochondria $(0.1 \pm$ $0.01 \mu \mathrm{m} / \mathrm{s}$; Fig. $\left.1 D ; p=1 \times 10^{-7}\right)$. Maximum instantaneous velocity was significantly greater in the processes of neurons $(0.7 \pm 0.04 \mu \mathrm{m} / \mathrm{s})$ compared with astrocytes $(0.4 \pm 0.04 \mu \mathrm{m} / \mathrm{s}$; Fig. $1 E ; p=0.0001)$. Mitochondrial length was also seen to be significantly greater in neurons $(4.7 \pm 0.3 \mu \mathrm{m})$ than in astrocytes $(2.4 \pm 0.2 \mu \mathrm{m}$; Fig. $1 F ; p=0.002)$. It can therefore be concluded that, although mitochondria are mobile in the processes of astrocytes, their trafficking dynamics are slower than that observed in neurons. Astrocyte mitochondria were nevertheless capable of covering similar distances $(9.8 \pm 1.1 \mu \mathrm{m})$ compared with mitochondria in neurons $(11.9 \pm 1.2 \mu \mathrm{m}$; Fig. $1 G ; p=0.2)$.

\section{Enhancing neuronal activity alters mitochondrial trafficking dynamics and morphology in astrocytic processes in situ} We subsequently addressed the important question of whether neuronal activity alters mitochondrial trafficking and morphology in astrocytic processes, using rat hippocampal slices transduced with AV-mtdsRed2-ires-EGFP (Fig. $2 A$ ). An acute (5 min) treatment of glutamate $(100 \mu \mathrm{M}+1 \mu \mathrm{M}$ glycine $)$, to activate glutamate receptors (Fig. $2 A, A i)$, or 4 -AP $(100 \mu \mathrm{M})$ to stimulate neuronal activity significantly reduced mitochondrial mobility (Fig. $2 B ; p<0.0001$ and $p<0.0001$ ) and velocity (Fig. $2 C$; $p=$ 0.001 and $p=0.0003$, respectively) in the processes of astrocytes. The reduction in mitochondrial mobility and velocity induced by glutamate and 4-AP recovered to basal levels 15 and $30 \mathrm{~min}$ following treatment, respectively, showing that these alterations are transient (Fig. 2B,C). In addition, omitting extracellular $\mathrm{Ca}^{2+}$ from the perfusion media, along with EGTA $(100 \mu \mathrm{M})$ to chelate any existing $\mathrm{Ca}^{2+}$, blocked the reduction in mitochondrial mobility and velocity induced by glutamate (Fig. $2 B, C ; p>0.9$ and $p=0.3$, respectively). Omitting extracellular $\mathrm{Ca}^{2+}$ also blocked the 4-AP-induced alterations in mobility and velocity (Fig. $2 B, C$; $p=0.5$ and $p=0.1$, respectively). This suggests that neuronal activity induces astrocyte $\mathrm{Ca}^{2+}$ elevations, which regulates astrocyte mitochondrial trafficking dynamics. Conversely, blocking neuronal activity with TTX $(1 \mu \mathrm{M})$ for 30 min significantly increased astrocyte mitochondrial mobility (Fig. $2 B ; p=0.04$ ) but 

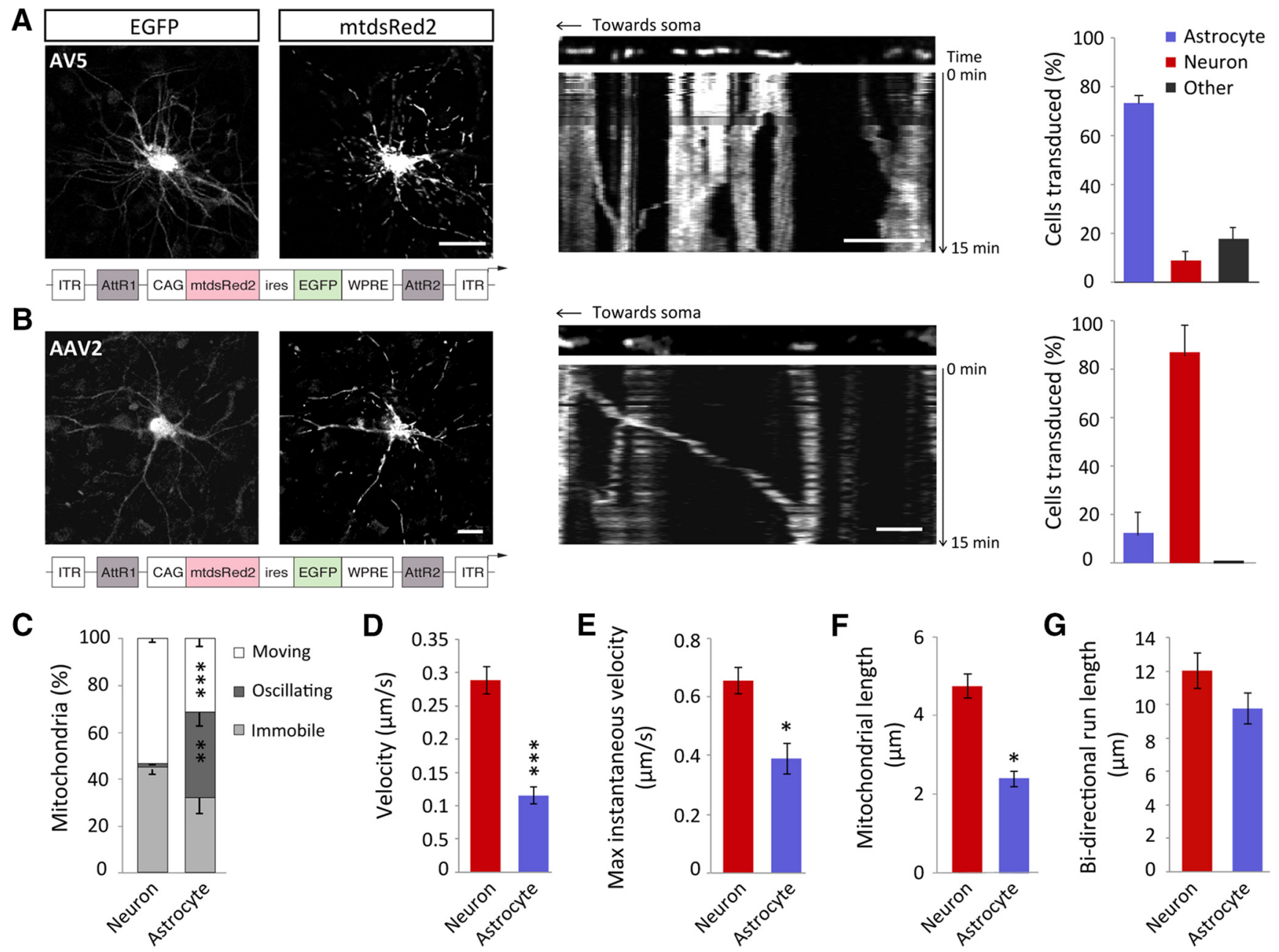

Figure 1. Basal mitochondrial trafficking dynamics differ in astrocytic processes compared with neuronal processes in situ. A, Representative confocal images of an organotypic slice hippocampal astrocyte transduced with an AV-5-expressing mtdsRed2 and EGFP driven by a CAG promoter. Inset, Example kymograph showing representative basal mitochondrial trafficking over a 15 min period with AV transduction. Scale bar, $15 \mu \mathrm{m}$; inset, $5 \mu \mathrm{m}$. Far right, Inset, Indicates viral tropism of AV where an increased percentage of cells transduced colocalize with GFAP. $\boldsymbol{B}$, Example of an organotypic slice hippocampal neuron transduced with an AAV-2-expressing mtdsRed2 and EGFP driven by a CAG promoter. Scale bars, $15 \mu \mathrm{m}$. Inset, Example kymograph showing representative basal mitochondrial trafficking over a 15 min period with AAV transduction. Scale bar, $15 \mu \mathrm{m}$; inset, $5 \mu \mathrm{m}$. Far right, Inset, Viral tropism of AAV where an increased percentage of cells transduced colocalize with MAP2. C, Basal mitochondrial mobility in astrocytes and neurons, defined as moving, oscillating or immobile (neurons: $n=4$ cells, 4 slices; astrocytes: $n=7$ cells, 7 slices). D, Basal velocity (speed) of moving mitochondria in astrocytic processes and neuronal dendrites. Mitochondria moved $>2 \mu$ m during the period of imaging (neurons: $n=21$ mitochondria, 8 cells, 8 slices; astrocytes: $n=20$ mitochondria, 9 cells, 9 slices). $\boldsymbol{E}$, Maximal instantaneous velocity of moving mitochondria in astrocytic processes and neuronal dendrites (neurons: $n=21$ mitochondria, 8 cells, 8 slices; astrocytes: $n=20$ mitochondria, 9 cells, 9 slices). $\boldsymbol{F}$, Mitochondrial length in astrocytic processes and neuronal dendrites (neurons: 3 cells, 3 slices; astrocytes: 3 cells, 3 slices). $\boldsymbol{G}$, Bidirectional run length of moving mitochondria in astrocytic processes and neuronal processes (neurons: $n=21$ mitochondria, 8 cells, 8 slices; astrocytes: $n=20$ mitochondria, 9 cells, 9 slices). ${ }^{*} p<0.05$, ${ }^{* *} p<0.01,{ }^{* * *} p<0.001$.

not velocity (Fig. $2 C ; p=0.4$ ). This reveals that mitochondrial trafficking is regulated by neuronal activity and confirms that blocking neuronal activity increases mitochondrial mobility in astrocytes (Jackson et al., 2014).

We further investigated which glutamate receptors are important for regulating glutamate receptor-dependent mitochondrial stopping in astrocytes. AMPA receptors and metabotropic glutamate receptors (mGluRs) have been shown to play an important role in increasing astrocytic $\mathrm{Ca}^{2+}$ (Araque et al., 2001; D'Ascenzo et al., 2007; Srinivasan et al., 2015) and we investigated whether these were involved in our system. In the presence of the AMPA receptor blocker NBQX $(50 \mu \mathrm{M})$, glutamate treatment still caused a significant reduction in mitochondrial mobility $(p<0.0001)$ that was not significantly different to the reduction observed upon glutamate treatment $(p>0.9)$. Mitochondrial mobility was also significantly reduced when glutamate was added together with the broad-spectrum mGluR blocker MCPG (1 mM; $p<$
$0.0001)$, however, not to the same degree as with glutamate alone $(p=0.02)$, suggesting a partial involvement of mGluRs in the glutamate-dependent stopping of mitochondria in astrocytic processes. In contrast, when the NMDAR blocker D-APV (50 $\mu \mathrm{M}$ ) was added during glutamate treatment there was no significant reduction in mitochondrial mobility $(p=>0.9)$, demonstrating that activation of NMDARs is a major pathway in the glutamate-dependent control of astrocyte mitochondrial mobility.

Glutamate treatment also greatly reduced mitochondrial length (Fig. $2 D ; p<0.001$ ), which was reversed $24 \mathrm{~h}$ following glutamate treatment (Fig. $2 D ; p=0.9$ ) suggesting that the changes in mitochondrial morphology are not cytotoxic. The effects of glutamate treatment on morphology were blocked when extracellular $\mathrm{Ca}^{2+}$ was removed (Fig. $2 D ; p>0.9$ ). Mitochondrial shortening was also blocked upon NMDAR blockade with MK-801 (100 $\mu \mathrm{M}$; Fig. 2D; $p>0.9$ ), whereas NBQX (50 $\mu \mathrm{M})$ had no effect (Fig. $2 D ; p<0.001$ ). In addition, stimulating neu- 
A

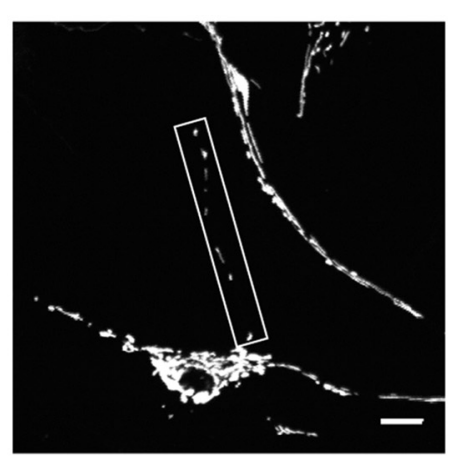

B

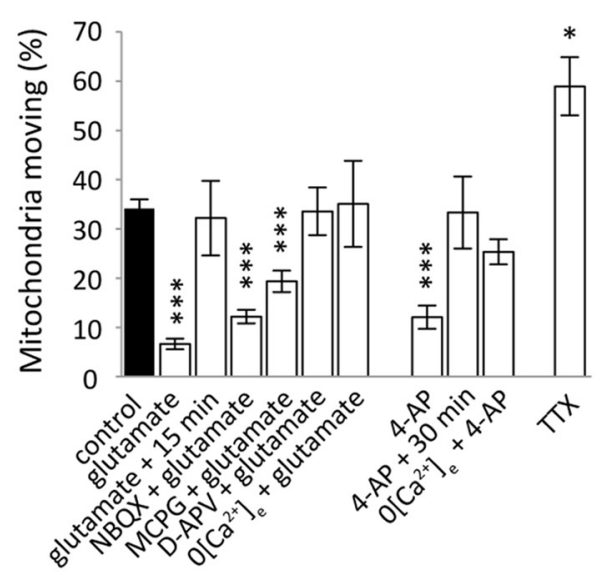

Ai Imaging protocol

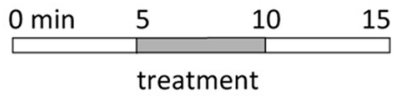

$\longleftarrow$ Towards soma

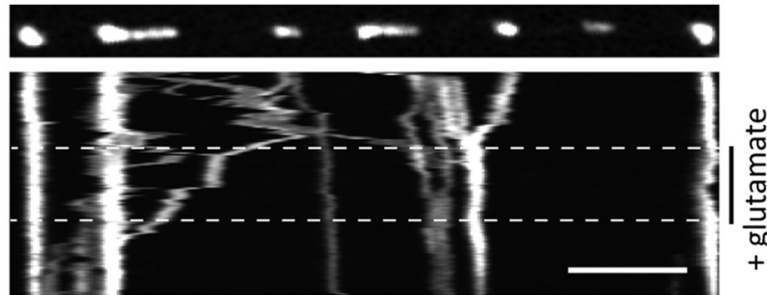

C

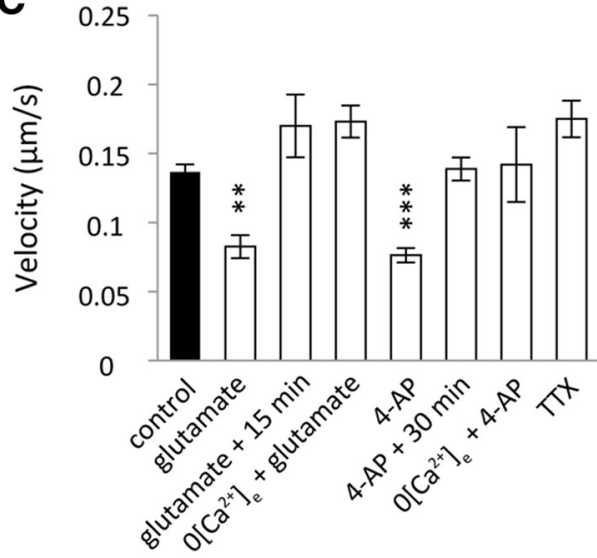

D

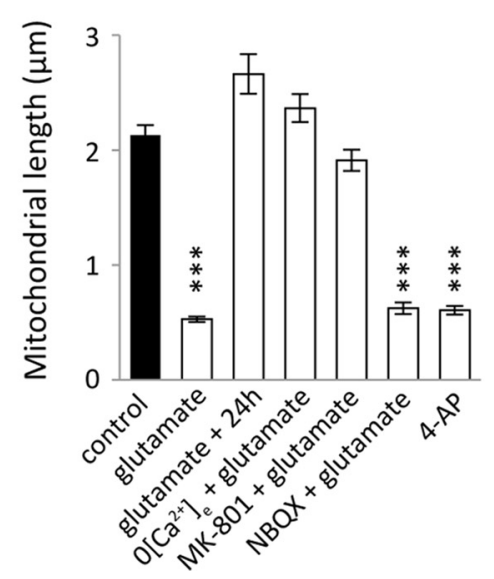

E

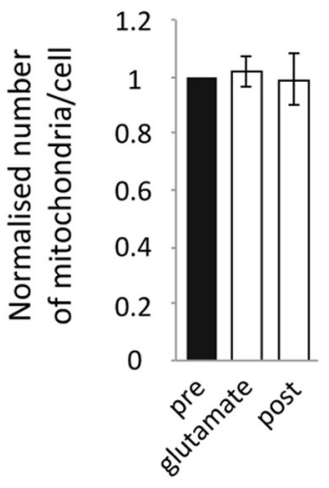

F

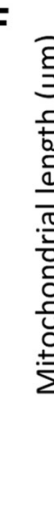

Pure astrocyte

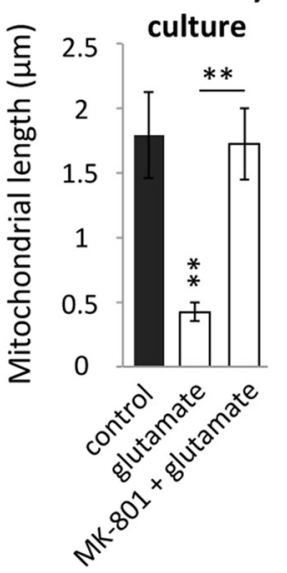

Figure 2. Enhancing neuronal activity alters mitochondrial trafficking dynamics and morphology in astrocytic processes in situ. A, Representative confocal image of an organotypic slice hippocampal astrocyte AV-transduced with mtdsRed 2 and EGFP. Scale bar, $5 \mu \mathrm{m}$. Ai, Imaging protocol where drug treatments (unless otherwise stated) were perfused while imaging for 5 min after a 5 min period of imaging basal trafficking and imaged 5 min after treatment. Example kymograph shows mitochondrial trafficking before (pre), during and after (post) glutamate treatment (100 $\mu \mathrm{m}$ glutamate $+1 \mu \mathrm{m}$ glycine). Scale bar, $5 \mu \mathrm{m}$. B, Mitochondrial mobility in situ, defined as percentage moving, in the 5 min period post-treatment [excluding glutamate +15 min and 4-AP + 30 min; control (combined pre): $n=39$ cells, 36 slices; glutamate: $n=8$ cells, 8 slices; glutamate +15 min: $n=3$ cells, 3 slices; NBQX ( $50 \mu \mathrm{m}$ ) + glutamate: $n=11$ cells, 11 slices; MCPG ( 1 mM) + glutamate: $n=12$ cells, 7 slices; D-APV $(50 \mu \mathrm{m})+$ glutamate: $n=5$ cells, 3 slices; $0\left[\mathrm{Ca}^{2+}\right]_{\mathrm{e}}+$ glutamate: $n=4$ cells, 3 slices; $4 \mathrm{AP}(100 \mu \mathrm{m}): n=7$ cells, 7 slices; 4 -AP +30 min: $n=3$ cells, 3 slices; $0\left[\mathrm{Ca}^{2+}\right]_{\mathrm{e}}+4$-AP: $n=4$ cells, 4 slices; TTX $(1 \mu \mathrm{M}): n=3$ cells, 3 slices). C, Velocity of moving mitochondria 5 min post-treatment (excluding glutamate +15 min and 4-AP +30 min; control (combined pre): $n=38$ mitochondria, 36 slices; glutamate $n=13$ mitochondria, 4 slices; glutamate $+15 \min n=23$ mitochondria, 3 slices; $0\left[\mathrm{Ca}^{2+}\right]_{\mathrm{e}}+\mathrm{glutamate} n=11$ mitochondria, 4 slices; 4 AP: $n=11$ mitochondria, 4 slices; 4-AP +30 min: $n=18$ mitochondria, 4 slices; $0\left[\mathrm{Ca}^{2+}\right]_{\mathrm{e}}+4-\mathrm{AP}: n=12$ mitochondria, 4 slices; TTX: $n=16$ mitochondria, 3 slices). D, Quantification of mitochondrial length post-treatment in situ (control: $n=53$ cells, 53 slices; glutamate: $n=58$ cells, 58 slices; glutamate $+24 \mathrm{~h}: n=10$ cells, 10 slices; $0\left[\mathrm{Ca}^{2+}\right]_{\mathrm{e}}+$ glutamate: $n=24$ cells, 24 slices; MK-801 (100 $\mu \mathrm{m})+$ glutamate: $n=24$ cells, 24 slices; NBQX + glutamate: $n=25$ cells, 25 slices; 4 AP: $n=11$ cells, 11 slices). E, Normalized number of mitochondria before, during, and after live glutamate treatment in situ (pre: $n=3$ cells, 3 slices; glutamate: $n=3$ cells, 3 slices; post: $n=3$ cells, 3 slices). $\boldsymbol{F}$, Mitochondrial length post-treatment in pure cortical astrocyte cultures with glutamate treatment and glutamate + MK-801 (100 $\mu \mathrm{m}$; control and glutamate treatment: $n=7$ cells; glutamate + MK-801: $n=10$ cells). ${ }^{*} p<0.05,{ }^{* *} p<0.01,{ }^{* * *} p<0.001$.

ronal activity with 4-AP $(100 \mu \mathrm{M})$ dramatically decreased mitochondrial length (Fig. $2 D ; p<0.001$ ).

To establish whether glutamate treatment-induced mitochondrial remodeling or fission, the total number of mitochon- dria along the process was quantified before, during, and after glutamate treatment within the same cell. Glutamate treatment did not appear to alter the average number of mitochondria suggesting mitochondrial remodeling is occurring and not fission 
A
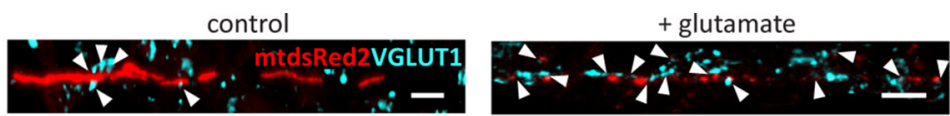

B

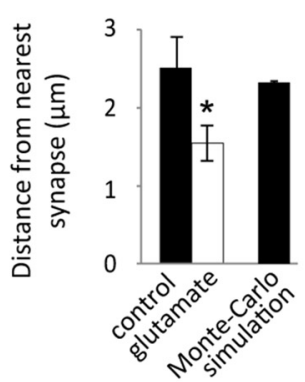

C

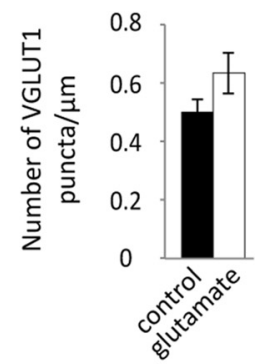

$\nabla$ sites of close proximity

D
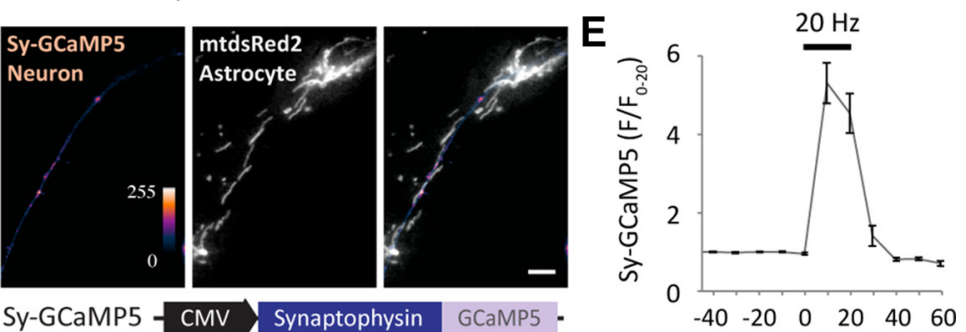

$\mathbf{F}$ Sy-GCaMP5 -CMV Synaptophysin GCaMP5 -

\section{G}
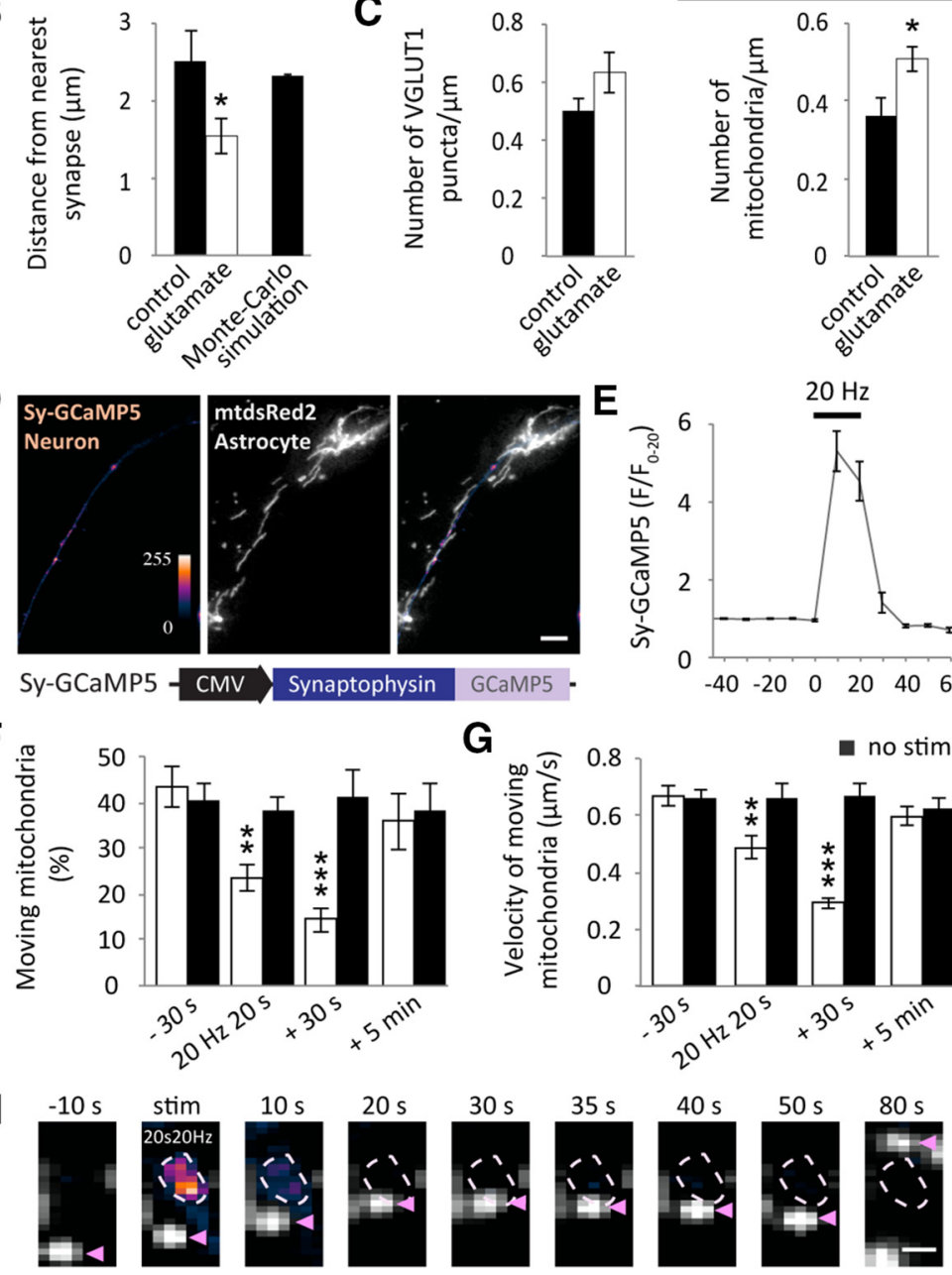

H
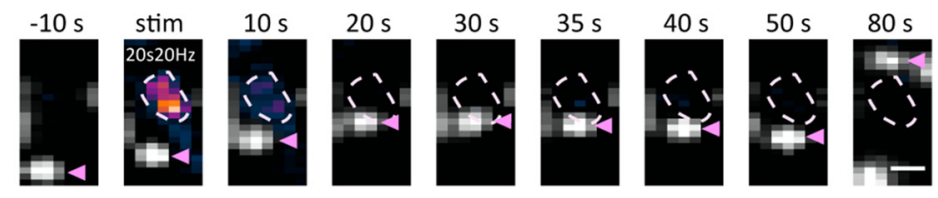

I

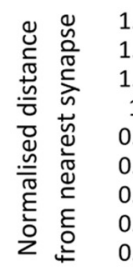

$\left.\begin{array}{l}1.3 \\ 1.2 \\ 1.1 \\ 1 \\ 0.9 \\ 0.8 \\ 0.7 \\ 0.6 \\ 0.5\end{array}\right]$
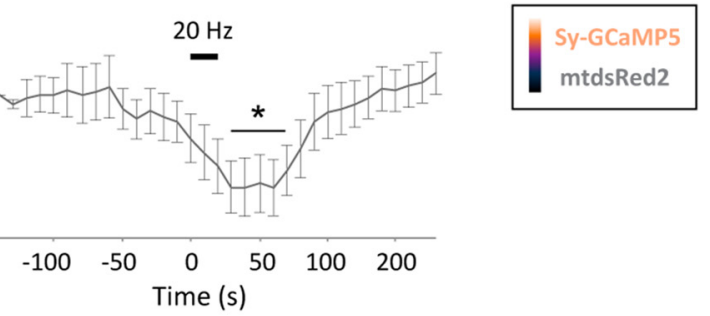

$\mathbf{J}$
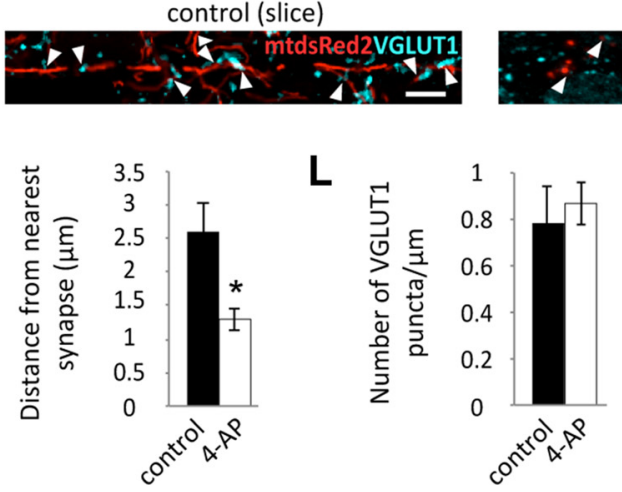

+4-AP (slice)
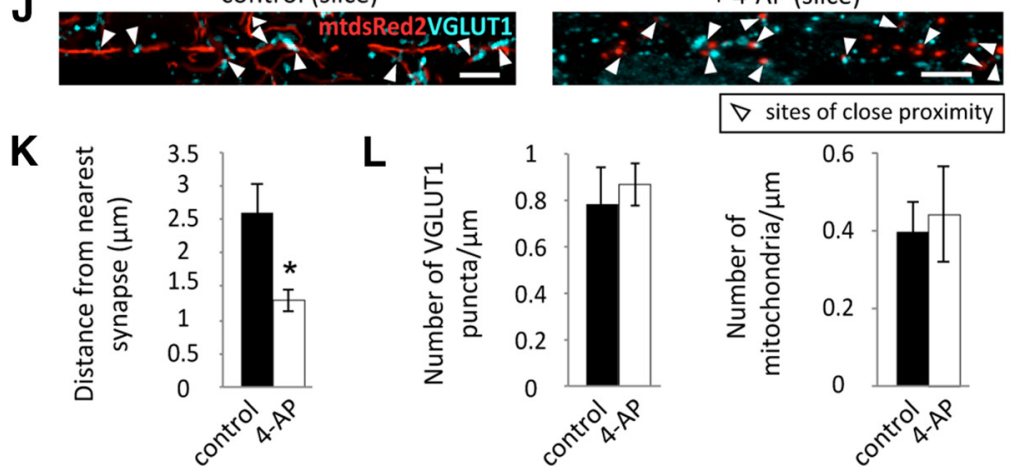

$\nabla$ sites of close proximity

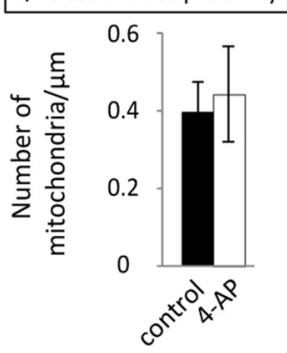

Figure 3. Neuronal activity induces astrocyte mitochondrial positioning near synapses. $A$, Representative images of astrocytic processes (cultured astrocytes in the presence of neurons) transduced with AV-mtdsred2-ires-EGFP and synapses immunolabeled with VGLUT1. Scale bars, $5 \mu \mathrm{m}$. Arrows show points of close proximity between astrocyte mitochondria and synapses. $\boldsymbol{B}$, The
(Fig. 2E; $p>0.9$ ). In astrocytes cultured in the absence of neurons, glutamate alone decreased mitochondrial length, an effect that was blocked with MK-801 (Fig. 2F; $p=0.001)$. This result suggests that glutamate could be acting directly on astrocyte NMDARs to mediate $\mathrm{Ca}^{2+}$ entry resulting in mitochondrial remodeling in addition to a reduction in mobility. Together it

\section{$\leftarrow$}

distance between each mitochondrion and its nearest VGLUT1-labeled synapse under basal conditions and with glutamate treatment ( $5 \mathrm{~min}, 100 \mu \mathrm{m}+1 \mu \mathrm{m}$ glycine). 2D Monte Carlo-simulated representation of random distribution shows that under control conditions, mitochondria are randomly distributed in relation to synapses (control: $n=6$ ROls, 6 cells; glutamate: $n=7$ Rols, 7 cells). C, Number of mitochondria and VGLUT1 puncta in analyzed ROIs, per micrometer (control: $n=6$ ROls, 6 cells; glutamate: $n=7$ ROls, 7 cells). D, Synaptically targeted GCaMP5 (Sy-GCaMP5) was made by tagging GCaMP5 to a synaptophysin targeting sequence. Representative wide-field images of hippocampal neurons transfected with Sy-GCaMP5 (pseudo-colored) and cocultured with hippocampal astrocytes pre-transfected with mtdsRed2 (gray). Cocultures were maintained for 3-4 DIV before imaging. Scale bar, $10 \mu \mathrm{m}$. E,Sy-GCaMP5 response to field stimulation $(20 \mathrm{~Hz}$ for $20 \mathrm{~s}$ ). Background signal at each corresponding time point was subtracted from the Sy-GCaMP5 signal before normalizing to the first 20 frames $\left(F / F_{0-20} ; n=12\right.$ cells). $F$, Percentage of mitochondria moving before, during, $30 \mathrm{~s}$ following stimulation and 5 min poststimulation, compared with prestimulated controls (white bars). Black bars represent mitochondrial mobility in the absence of stimulation at the same time points ( -30 s and stim: $n=11$ cells; 30 s post-stim: $n=9$ cells; 5 min post-stim: $n=6$ cells; -30 s and no stim: $n=9$ cells $; 30$ s post-no stim: $n=7$ cells; 5 min post-no stim: $n=5$ cells). $\mathbf{G}$, Velocity of moving mitochondria before, during stimulation, $30 \mathrm{~s}$ poststimulation and 5 min poststimulation compared with prestimulated controls ( $-30 \mathrm{~s}$ stim: $n=30$ mitochondria, 11 cells; stim: $n=27$ mitochondria, 11 cells; 30 s poststim: $n=24$ mitochondria, 9 cells; 5 min post-stim: $n=21$ mitochondria, 6 cells; -30 s no stim: $n=24$ mitochondria, 9 cells; no stim: $n=18$ mitochondria, 9 cells; 30 s post-no stim: $n=18$ mitochondria, 7 cells; 5 min post-no stim: $n=18$ mitochondria, 5 cells). $\boldsymbol{H}$, Example Sy-GCaMP5 labeled synapse and nearby astrocyte mitochondrion, labeled with mtdsRed2. Following stimulation the marked mitochondrion moves closer to its nearest synapse (within $30 \mathrm{~s}$ ) where it remains confined for $\sim 20 \mathrm{~s}$. Approximately $50 \mathrm{~s}$ following stimulation the mitochondrion indicated begins to move away from its nearest synapse. Scale bar, $1 \mu \mathrm{m}$. $I$, Normalized distance of mitochondria to their respective nearest synapses $(<15 \mu \mathrm{m})$. Mitochondria move closer to their nearest synapse, temporarily, following field stimulation ( $20 \mathrm{~Hz} 20 \mathrm{~s})$. Astrocyte mitochondria become confined within $30 \mathrm{~s}$ and move away $\sim 80$ s following stimulation ( $n=12$ mitochondria, 8 cells). J, Representative images of AV-mtdsred2-ir-EGFP transduced hippocampal slices immunolabeled with VGLUT1 (showing mtdsRed2-VGLUT1 merge) in control conditions and with 4-AP treatment (5 min, $100 \mu \mathrm{m}$ ). Scale bars, $5 \mu \mathrm{m} . \boldsymbol{K}$, Distance between mitochondria and theirnearestVGLUT1-labeled synapse under basal conditions and following 4-AP treatment (control: $n=6$ cells, 3 slices; 4-AP: $n=5$ cells, 3 slices). L, Number of mitochondria and VGLUT1 puncta in analyzed ROIs, per micrometer (control: $n=6$ ROls, 3 slices; 4-AP: $n=5$ ROls, 3 slices). ${ }^{*} p<0.05,{ }^{* *} p<0.01,{ }^{* * *} p<0.001$. 
can be concluded that neuronal activity regulates mitochondrial trafficking and morphology in astrocytic processes. We suggest that this regulation is mediated by ionotropic glutamate receptor activation inducing astrocyte $\mathrm{Ca}^{2+}$ elevations.

\section{Neuronal activity induces astrocyte mitochondrial positioning near synapses}

We next investigated whether mitochondria in astrocytic processes position themselves near synapses and whether this is regulated directly by neuronal activity. Hippocampal astrocytes, cocultured with hippocampal neurons, were AV-transduced to label astrocyte mitochondria with $\mathrm{mtdsRed} 2$ and synapses were immunolabeled with VGLUT1 (a marker of presynaptic terminals; Fig. 3A). Under control conditions, the distance between the mitochondria and their nearest synapse was similar to a $2 \mathrm{D}$ Monte Carlo simulation of randomized distribution (Fig. 3B), using the same imaging parameters. Following glutamate treatment ( $5 \mathrm{~min}, 100 \mu \mathrm{M}+1 \mu \mathrm{M}$ glycine), a significant decrease was seen in the distance between the center of each astrocyte mitochondrion and its nearest VGLUT1 puncta (synapse) compared with untreated controls (Fig. $3 B ; p=0.04$ ). Importantly, there was no change in synapse number (per $\mu \mathrm{m}$; Fig. $3 C$; $p=0.2$ ). Together, this reveals that glutamate triggers mitochondrial retention near synapses in culture.

Applying electrical field stimulation (a more physiological form of neuronal stimulation) also altered mitochondrial trafficking dynamics in astrocytic processes. Hippocampal neurons were transfected with synaptically targeted GCaMP5 (SyGCaMP5) to label active synapses and cocultured with astrocytes pre-transfected with mtdsRed2 (Fig. 3D). This again, allowed separation of the astrocyte mtdsRed 2 signal and the neuronal Sy-GCaMP5 signal to observe the effects of stimulating neuronal activity on astrocyte mitochondrial dynamics. Upon field stimulation $(20 \mathrm{~Hz}$ for $20 \mathrm{~s}$ ), a fourfold increase was observed in SyGCaMP5 signal, showing that field stimulation drives increased neuronal and synaptic activity (Fig. $3 E$ ). Stimulation decreased the mobility (percentage moving; Fig. $3 F ; p=0.01, p=0.0001$ at 20 and $30 \mathrm{~s}$, respectively) and velocity (Fig. $3 G ; p=0.004, p=2 \times$ $10^{-6}$ at 20 and $30 \mathrm{~s}$, respectively) of moving mitochondria in astrocytes compared with pre-stimulated controls. The decrease in mobility and velocity recovered within 5 min following stimulation, showing that these alterations are transient (Fig. $3 F, G$ ). Alongside this, mitochondria repositioned themselves near activated synapses. The example mitochondrion is recruited to it's nearest activated synapse within $20 \mathrm{~s}$ following electrical stimulation $(20 \mathrm{~Hz} 20 \mathrm{~s})$, where it remains for $\sim 30 \mathrm{~s}$ before moving away (Fig. $3 H$ ). When analyzing the average of many mitochondria, the decrease in the distance between astrocyte mitochondria and their corresponding nearest activated synapse occurred within the first $30 \mathrm{~s}$ following electrical stimulation $(20 \mathrm{~Hz} 20 \mathrm{~s}$; Fig. 3I; $p=0.003,0.007,0.009,0.005$ and 0.008 , at $30 \mathrm{~s}, 40 \mathrm{~s}, 50 \mathrm{~s}$, 60 and $70 \mathrm{~s}$, respectively). Mitochondria remain confined within close proximity to their nearest activated synapse for $\sim 50 \mathrm{~s}$ and then begin to move away $\sim 80 \mathrm{~s}$ following stimulation (Fig. $3 I$ ). Similar to astrocytes in culture, mitochondria in situ also became confined near synapses when neuronal activity was stimulated with 4-AP (5 min, $100 \mu \mathrm{M})$. In slices, astrocytes were AVtransduced to label mitochondria with mtdsRed 2 and synapses were immunolabeled with VGLUT1 (Fig. 3J). 4-AP treatment led to a significant reduction in the distance of mitochondria to their nearest synapse (Fig. $3 K ; p=0.02$ ), without causing a significant change in mitochondria or synapse number (per $\mu \mathrm{m}$; Fig. $3 L ; p=$ $0.7, p=0.7)$. These data indicate that, in addition to a decrease in mitochondrial trafficking dynamics, stimulating neuronal activity induces astrocyte mitochondrial confinement near synapses in dissociated culture and in situ.

Glutamate decreases the rate of mitochondrial fusion in astrocytic processes in situ

To further investigate mitochondrial dynamics in astrocytes a fusion assay was set up in organotypic slices using time-lapse confocal microscopy and the photo-switchable fluorescent protein, Dendra2 (Gurskaya et al., 2006), targeted to the mitochondrial matrix (mito-dendra2). Dendra2 fluoresces green and switches to red when photo-activated with $405 \mathrm{~nm}$ (UV) light. The photoconversion is irreversible, nontoxic, and stable making mito-dendra2 ideal for observing fusion of labeled mitochondria when a small subset is photoconverted (Magranéet al., 2012; Pham et al., 2012). A transgenic mouse line expressing a loxPflanked termination signal upstream of the mito-dendra2 (loxPstop-loxP-mito-dendra2) only allows mito-dendra2 expression when CRE is present (Pham et al., 2012). This allowed specific mito-dendra2 expression in astrocytes with infection of an AV encoding CRE (AV-CRE; Fig. 4A). Specific expression in astrocytes was confirmed by the colocalization of the mito-dendra2 signal with GFAP and not NeuN (Fig. 4B). Upon photoconversion of a small subset of mito-dendra2 labeled mitochondria, fusion events between the red and the green mitochondria result in the transfer of fluorescence, which indicates mitochondrial matrix exchange (seen as a mixing of red and green-forming orange mitochondria; Fig. 4C; Magranéet al., 2012; Pham et al., 2012). In this system, mitochondrial fusion remained unchanged with glutamate treatment $(100 \mu \mathrm{M}+1 \mu \mathrm{M}$ glycine; Fig. $4 C$; compared with pre-switch, $p=>0.9,0.1,>0.9,0.9$, and $>0.9$, at 2,4 , 6,8 , and $10 \mathrm{~min}$, respectively), where the fusion rate significantly increased in untreated controls (Fig. 4D; compared with preswitch, $p=0.02,0.009,0.02,0.004$, and 0.001 , at $2,4,6,8$, and 10 $\mathrm{min}$, respectively). This suggests that glutamate alters mitochondrial morphology in astrocyte processes in situ, which may in part be due to a reduction in the fusion rate as a consequence of a reduction in mitochondrial mobility.

The $\mathrm{Ca}^{2+}$-sensing EF-hands of Miro1 are essential for regulating mitochondrial trafficking and morphology in astrocytes in primary culture

Previously, we have shown that Mirol plays an important role in regulating mitochondrial trafficking in neurons (Macaskill et al., 2009). This led us to investigate the potential role of Mirol in regulating activity-dependent mitochondrial trafficking in astrocytes. First, we observed that rodent astrocytes express both isoforms of Miro (Miro1 and Miro2; Fig. 5A). Immunolabeling Miro 1 and Miro2 along with AV-mtdsRed2-ires-EGFP transduction, in situ, revealed that Miro1 and Miro2 are localized to mitochondria in astrocytes (Fig. $5 B$ ).

To observe the role of Miro1 in regulating mitochondrial trafficking dynamics in astrocytes, astrocyte-neuron cocultures were transfected with either wild-type Miro1 (Miro1 ${ }^{\text {WT }}$ ) or EF-hand mutant Miro1 (Miro $1^{\mathrm{AEF}}$ ), which can no longer bind $\mathrm{Ca}^{2+}$ (Fig. 5C). We used vectors bicistronically expressing either Miro $1^{\text {WT }}$ or Mirol ${ }^{\Delta \mathrm{EF}}$ along with mtdsRed 2 and cotransfected GFAP promoter driven GFP (GFAP-driven GFP), to identify astrocytes (Fig. $5 D, E$ ). As a further control, astrocytes were transfected with mtdsRed 2 alone (not overexpressing Miro1) and GFAP driven-GFP. Interestingly, both Miro $1^{\mathrm{WT}}$ and Miro1 ${ }^{\triangle \mathrm{EF}}$ overexpression (OE) increased basal mitochondrial mobility (Fig. 5F; $p=0.02$ and $p=0.01$, respectively) and velocity (Fig. $5 G ; p=0.001$ and $p=0.01$, 
A
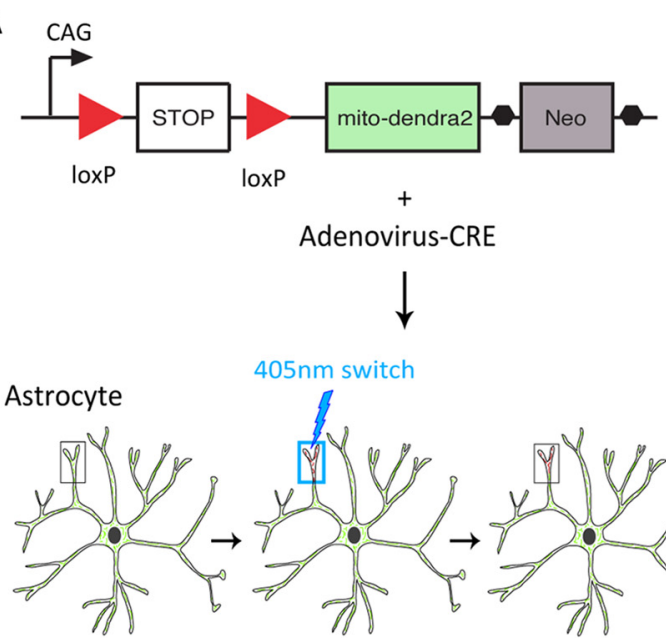

405nm switch

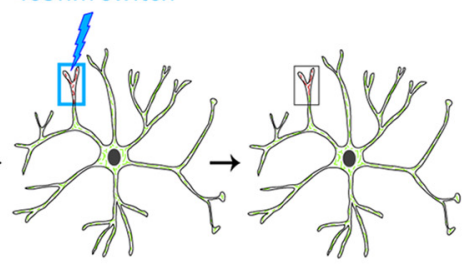

C
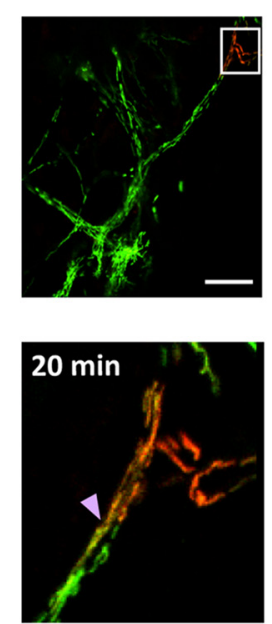

pre-switch
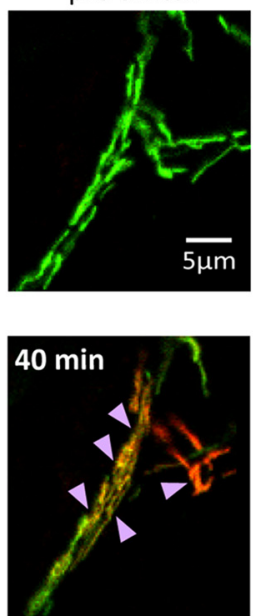

B
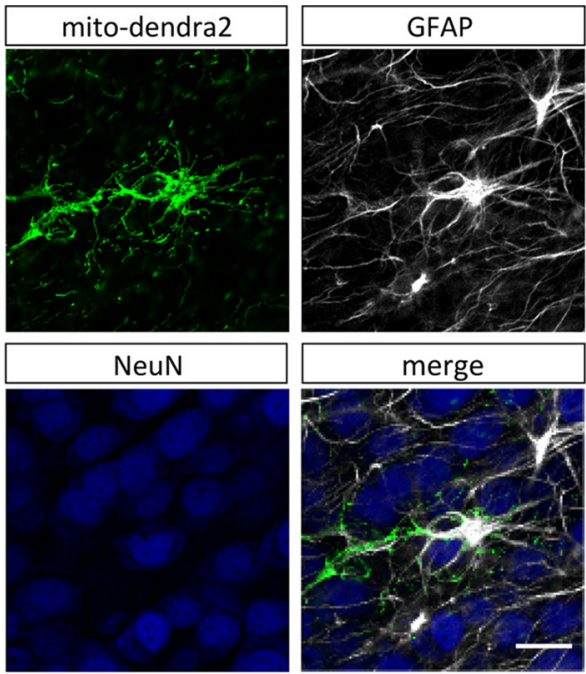
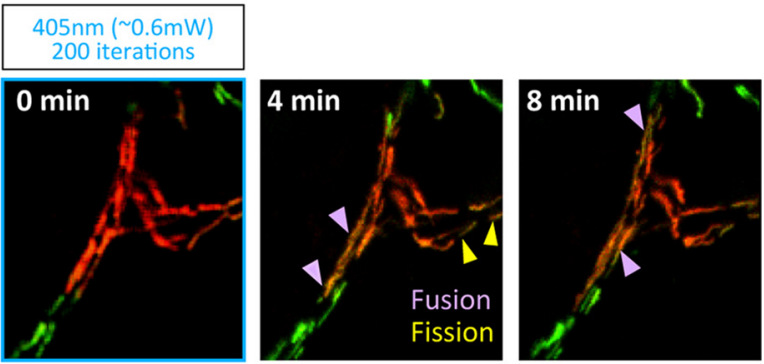

Fusion rate
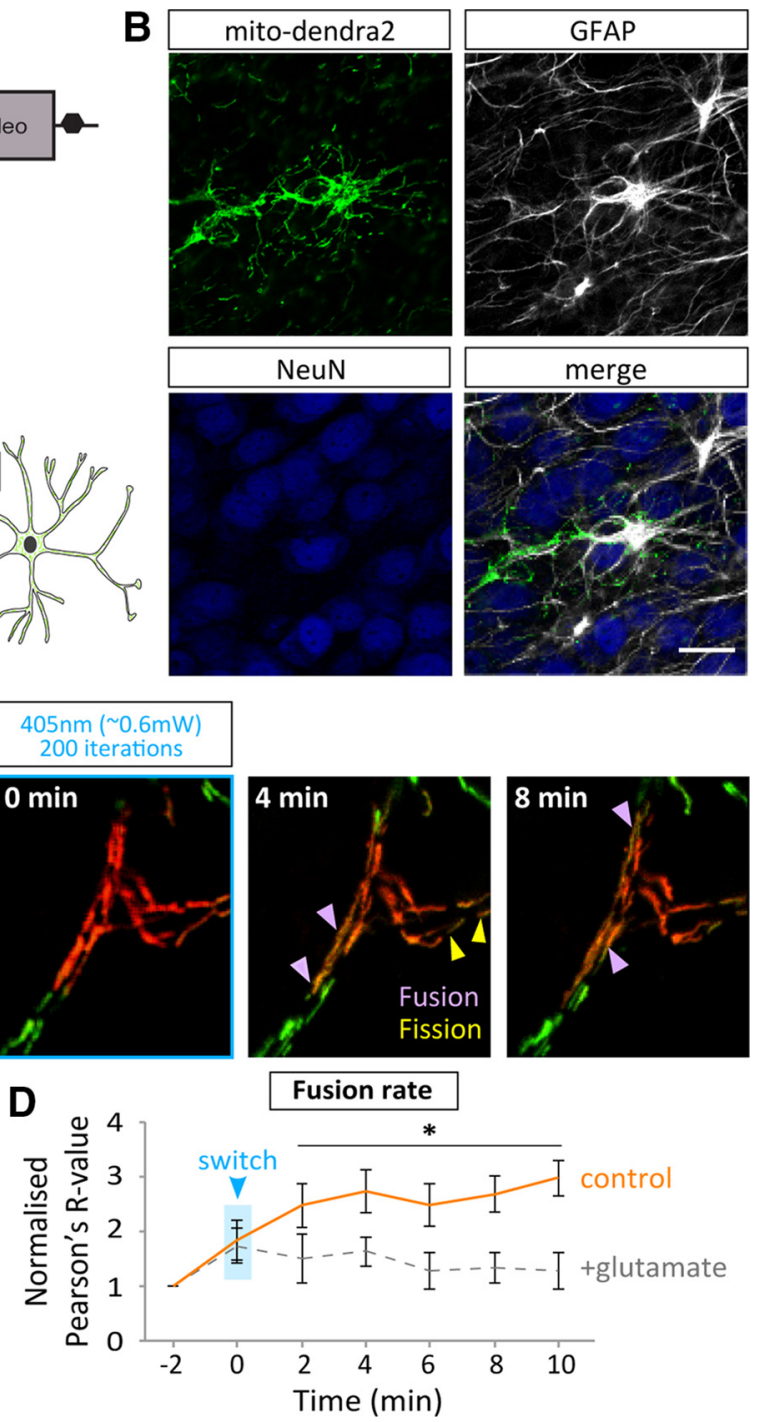

Figure 4. Glutamate decreases the fusion rate of mitochondria in astrocytic processes in situ. $A$, Schematic representation of CRE-driven mito-dendra2 expression in hippocampal slices. A mouse line expressing floxed-stop-mito-dendra2 infected with an AV-CRE allows astrocyte-specific expression. $\boldsymbol{B}$, Expression is shown to be astrocyte-specific as mito-dendra-2 colocalizes with GFAP (shown in merge). Scale bar, $20 \mu \mathrm{m}$. C, Representative image of mito-dendra2 expression with $18 \mu \mathrm{m}^{2}$ region of activation, before and $4-40$ min after 200 iterations of $20 \% 405 \mathrm{~nm}$ laser light $(\sim 0.6 \mathrm{~mW})$. ROl shows example fusion dynamics under basal conditions in a distal astrocytic process. Scale bar, $20 \mu \mathrm{m} ; \mathrm{ROI}, 5 \mu \mathrm{m}$. $D$, Quantification of the rate of fusion under basal conditions (control) and in the presence of glutamate (100 $\mu \mathrm{m}+1 \mu \mathrm{m}$ glycine). Single focal-plane Pearson's $R$ values (au) represent colocalization of green and red mito-dendra2 signal before and after switching with $405 \mathrm{~nm}$ laser light and subsequently imaged every $2 \mathrm{~min}$ (this is defined as the fusion rate, ie, change in $R$ value over a 10 min period; control: $n=5$ cells, 5 slices; glutamate: $n=$ 5 cells, 5 slices). ${ }^{*} p<0.05$.

respectively; pre-glutamate). This suggests that Miro1 regulates mitochondrial trafficking under basal conditions and that the EF-hands of Mirol are not necessary for binding of mitochondria to motor proteins. It is likely that Miro1 (Mirol ${ }^{\mathrm{WT}}$ or Miro1 ${ }^{\mathrm{EF}} \mathrm{OE}$ ) increases the binding of mitochondria to motor proteins, increasing basal mitochondrial mobility and velocity.

Following glutamate treatment $(100 \mu \mathrm{M}+1 \mu \mathrm{M}$ glycine, 5 min), compared with control conditions (mtdsRed2), mitochondrial mobility (Fig. 5F; $p=0.4$ ) and velocity (Fig. $5 G ; p=$ $0.9)$ were unchanged with Miro $1^{\text {WT }}$ OE. Interestingly, however, post-glutamate treatment, compared with either control conditions or cells expressing Miro ${ }^{\mathrm{WT}}$, mitochondrial mobility (Fig. 5F; $p=0.001$ and $p=0.0003$, respectively) and velocity (Fig. $5 G ; p=0.0008$ and $p=002$, respectively) were significantly increased with Miro ${ }^{\Delta \mathrm{EF}} \mathrm{OE}$ i.e., Miro1 ${ }^{\Delta \mathrm{EF}} \mathrm{OE}$ impairs glutamate-induced halting of astrocyte mitochondria, where mobility and velocity were similar to pretreatment conditions. This reveals a previously unrecognized role for Miro 1 in astrocytes, whereby its $\mathrm{Ca}^{2+}$-sensing abilities are important for regulating mitochondrial trafficking and inducing mitochondrial stopping in response to glutamate treatment.

Furthermore, the role of the EF-hands of Mirol in regulating astrocyte mitochondrial morphology was also investigated. Interestingly, with Miro ${ }^{\triangle \mathrm{EF}} \mathrm{OE}$ mitochondria were more elongated compared with Miro ${ }^{\text {WT }}$ OE but not significantly different from control (mtsdRed2) conditions (Fig. $5 \mathrm{H}$; $p=0.01)$. Following glutamate treatment, mitochondrial length was significantly reduced in control conditions and with Miro ${ }^{\text {WT }}$ OE compared with pretreatment conditions and compared with Miro ${ }^{\Delta \mathrm{EF}} \mathrm{OE}$ (Fig. $5 H ; p=0.0007$ and $p=$ 0.01). This suggests that the EF-hands of Mirol are also important for regulating mitochondrial morphology in astrocytes. It could be that through mutating the EF-hands Mirol's 
A

Pure astrocyte culture

E16 mouse P1 rat

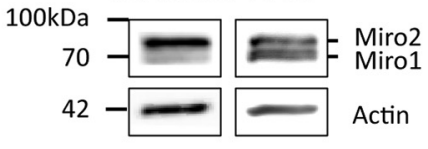

B

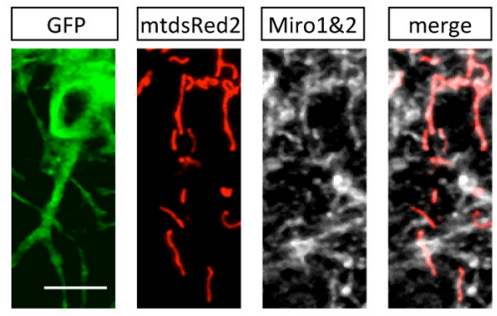

D

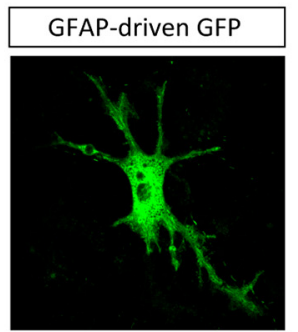

E

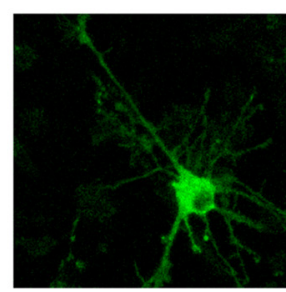

$\mathbf{F}$

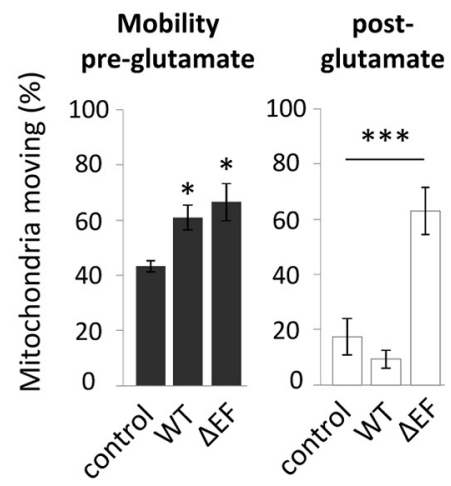

C

Dgtindaelnfaricfitp dCalspdelkdifkvfpyip Miro1 ${ }^{\text {Wt }}$

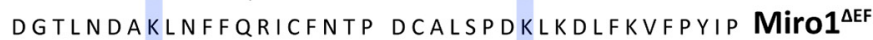
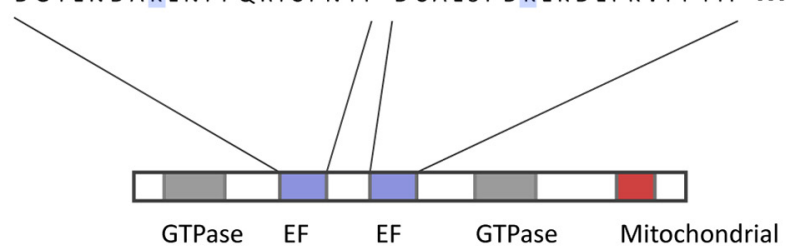

domain 1 hand 1 hand 2 domain 2 transmembrane domain

cytosol

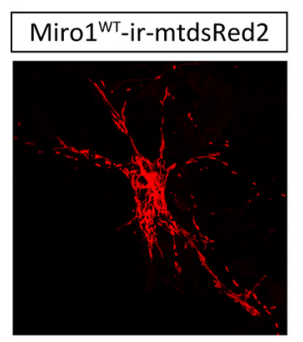

Miro1 ${ }^{\mathrm{AEF}}$-ir-mtdsRed2
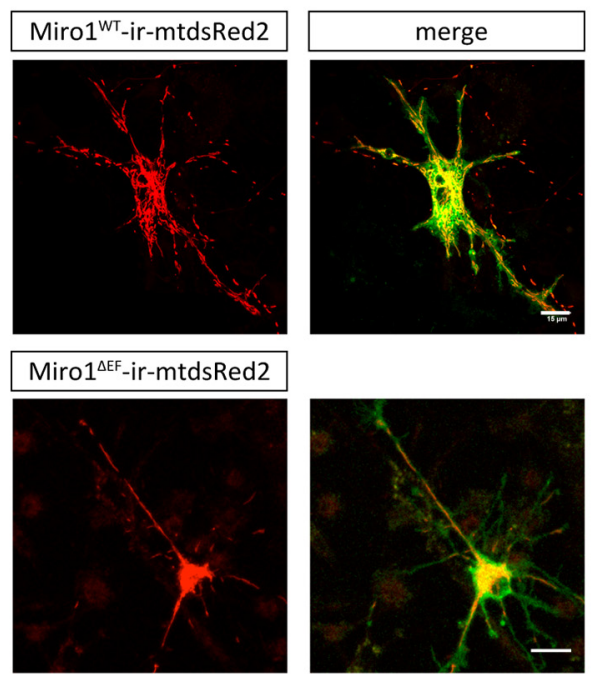

G

Velocity pre-glutamate

post-

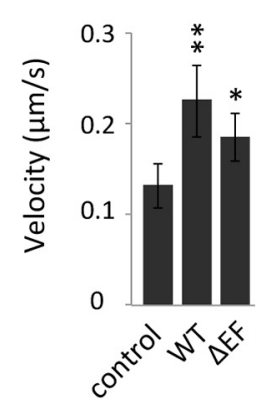
glutamate

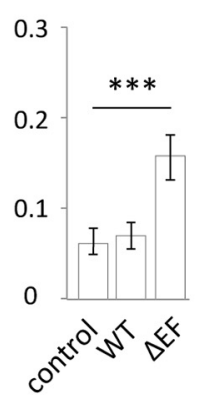

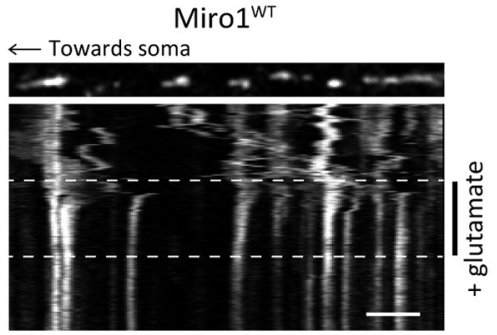

Miro1 $^{\mathrm{AEF}}$

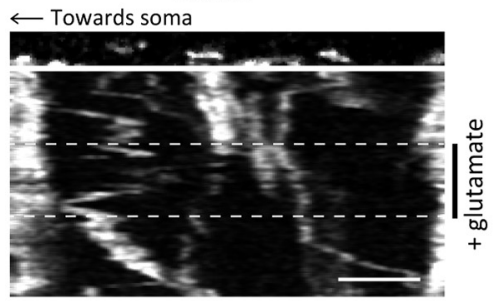

H

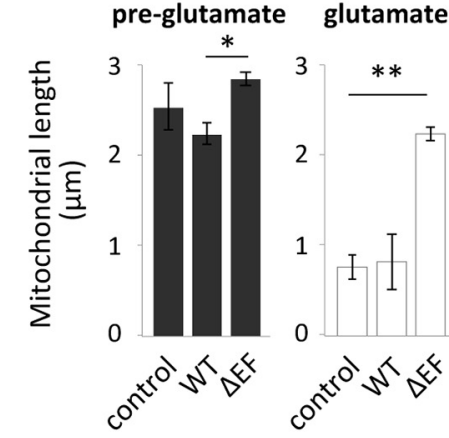

Figure 5. The $\mathrm{Ca}^{2+}$-sensing EF-hands of Miro1 are essential for regulating mitochondrial trafficking and morphology in astrocytes in primary culture. $\boldsymbol{A}$, Western blot analysis of endogenous Miro expression in cultured hippocampal mouse (E16) and rat (P1) astrocytes. B, Astrocytes, in situ, express Miro1, which localizes to mitochondria (hippocampal slice infected with AV-mtdsRed2-ires-EGFP and immunostained for Miro). Scale bar, $15 \mu \mathrm{m}$. C, Schematic of the primary structure of Miro1 showing two EF-hand Ca ${ }^{2+}$ binding domains flanked by two GTPase domains and a mitochondrial-binding domain. The schematic also shows the point mutations that exist in the mutant form of Miro ${ }^{\mathrm{EEE}-\mathrm{KK}}$ (Miro ${ }^{\Delta \mathrm{EF}}$ ), which cannot bind $\mathrm{Ca}^{2+} . \mathbf{D}$, Example images of Miro ${ }^{\text {WT }}$-ires-mtdsRed2 cotransfected with GFAP-driven GFP in a mixed culture. Scale bar, $15 \mu \mathrm{m}$. Inset, A representative kymograph of mitochondrial trafficking with glutamate treatment (100 $\mu \mathrm{M}+1 \mu \mathrm{m}$ glycine, $5 \mathrm{~min}$ ) with Miro1 ${ }^{\mathrm{WT}}$-ires-mtdsRed2 overexpression (0E). Scale bar, $5 \mu \mathrm{m}$. E, Example images of

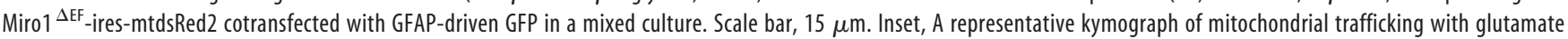
treatment (100 $\mu \mathrm{M}+1 \mu \mathrm{m}$ glycine, $5 \mathrm{~min}$ ) with Miro ${ }^{\mathrm{EEF}}$-ires-mtdsRed2 0 E. Scale bar, $5 \mu \mathrm{m}$. $\boldsymbol{F}$, Mitochondrial mobility pre-glutamate treatment (left) and post-glutamate treatment (right). Control conditions express mtdsRed2 and GFAP-driven GFP [control (pre- and post-glutamate): $n=3$ cells; Miro ${ }^{\text {WT }}$ (pre- and post-glutamate): $n=3$ cells; Miro ${ }^{\Delta \mathrm{EF}}$ (pre- and post-glutamate): $n=4$ cells]. G, Mitochondrial velocity pre-glutamate treatment (left) and post-glutamate treatment (right; control pre: $n=10$ mitochondria, 3 cells; Miro $1{ }^{\text {WT }}$ pre: $n=$ 12 mitochondria, 3 cells; Miro ${ }^{\Delta \mathrm{EF}}$ pre: $n=11$ mitochondria, 4 cells; control post: $n=9$ mitochondria, 3 cells; Miro ${ }^{\text {WT }}$ post: $n=10$ mitochondria, 3 cells; Miro ${ }^{\Delta \mathrm{EF}}$ post: $n=13$ mitochondria, 4 cells). $\boldsymbol{H}$, Mitochondrial length (morphology) pre-glutamate treatment (left) and post-glutamate treatment (right; control pre and post: $n=3$ cells; Miro ${ }^{\text {WT }}$ pre and post: $n=3$ cells; Miro ${ }^{\Delta \mathrm{EF}}$ pre and post: $n=3$ cells). ${ }^{*} p<0.05,{ }^{* *} p<0.01,{ }^{* * *} p<0.001$. 
A Triple-expression system in organotypic slices

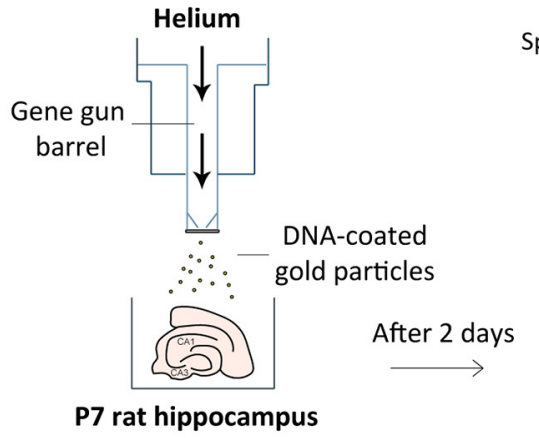

B
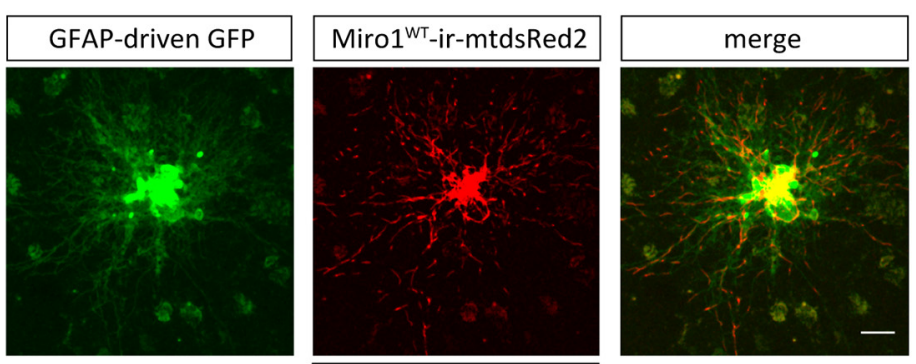

Miro1 ${ }^{\Delta E F-i r-m t d s R e d 2}$
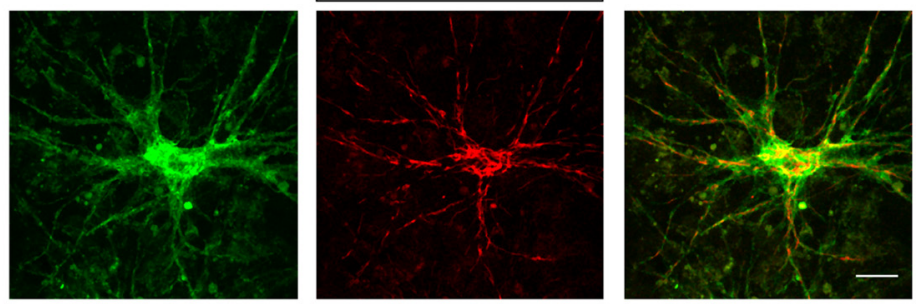

C

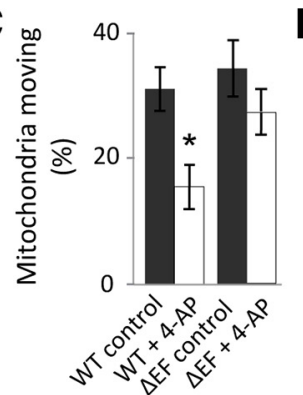

D

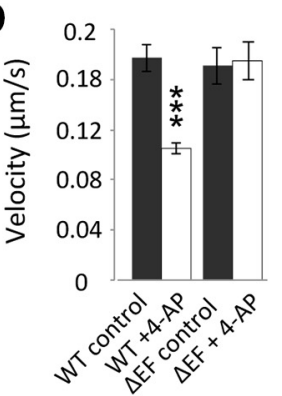

$\mathbf{E}$

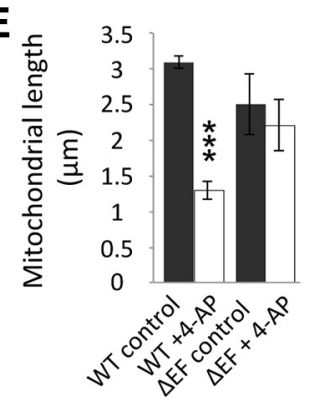

$\mathbf{F}$
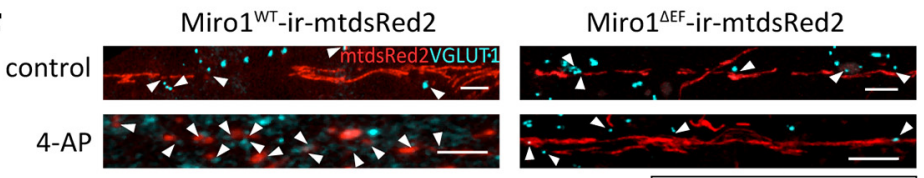

G

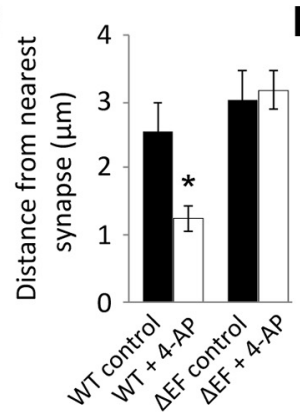

H

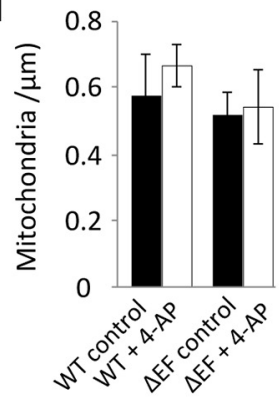

$\nabla$ sites of close proximity

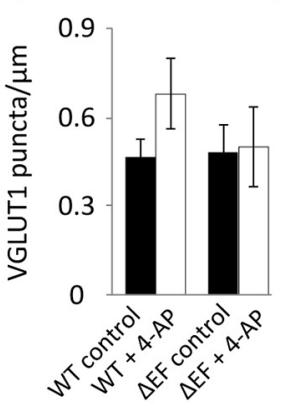

Figure 6. Mutant Miro1 (Miro ${ }^{\Delta \mathrm{EF}}$ ) expression, in situ, disrupts the ability of mitochondria to respond to neuronal activity and alters activity-driven astrocyte mitochondrial positioning near synapses. $\boldsymbol{A}$, Schematic representation of the biolistic interactions with pro-fission proteins, such as Drp1, are impaired (Saotome et al., 2008).

Mutant Miro1 (Miro1 ${ }^{\triangle E F}$ ) expression in situ disrupts the ability of mitochondria to respond to neuronal activity and alters activity-driven astrocyte mitochondrial positioning near synapses

To further investigate the role of Mirol in astrocytes in situ, we biolistically transfected organotypic slices with either Mirol $^{\mathrm{WT}}$ or Miro1 $^{\mathrm{DEF}}$, bicistronically expressing mtdsRed2, along with cotransfection of GFAP driven-GFP (Fig. 6A, $B$ ). Stimulating neuronal activity with 4 -AP resulted in a significant reduction in $\mathrm{mi}-$ tochondrial mobility (Fig. $6 C ; p=0.03$ ), velocity (Fig. $6 D ; p=9 \times 10^{-6}$ ), and length (Fig. $6 E ; p=0.0003$ ) in astrocytes, with Mirol ${ }^{\text {WT }} \mathrm{OE}$, which was not observed with Mirol ${ }^{\Delta \mathrm{EF}} \mathrm{OE}$ (Fig. $6 C-E ; p=$ $0.8, p=0.9$, and $p=0.6$, respectively). Subsequently, synapses were immunolabeled with VGLUT1 alongside astrocytes transfected with Mirol ${ }^{\text {WT }}$ or Mirol ${ }^{\Delta \mathrm{EF}}$ bicistronically expressing mtdsRed 2 to label mitochondria (Fig. 6F). The distance

triple-transfection system used to label astrocytes in slices. DNA of either Miro ${ }^{\mathrm{WT}}$-ires-mtdsRed2 or Miro ${ }^{\Delta \mathrm{EF}}$-iresmtdsRed2 was mixed with GFAP-driven GFP DNA and this mix was used to coat gold bullets. The standard biolistic transfection protocol for slices using a gene gun was subsequently followed. In this way sparse astrocytes express GFAP-driven GFP and either Miro ${ }^{\mathrm{WT}}$ or Miro ${ }^{\Delta \mathrm{EF}}$-ires-mtdsRed2. $\boldsymbol{B}$, Example confocal images of hippocampal slices biolistically transfected with GFAP-driven GFP and either Miro ${ }^{\text {WT }}$ or Miro ${ }^{\Delta \mathrm{EF}}$-ires-mtdsRed2 imaged 2-3 d post-shooting (slices were shot at 7 DIV). Scale bars, $15 \mu \mathrm{m}$. C, Mitochondria moving before (control) and after 4-AP treatment ( $100 \mu \mathrm{M}, 5 \mathrm{~min})$ with Miro1 ${ }^{\mathrm{WT}}$ and Miro ${ }^{\Delta \mathrm{EF}}$ overexpression (OE) [Miro ${ }^{\mathrm{WT}}$ (control and 4-AP): $n=3$ cells, 3 slices; Miro ${ }^{\Delta \mathrm{EF}}$ (control and $4-\mathrm{AP}): n=3$ cells, 3 slices]. D, Velocity of moving mitochondria before and after 4 -AP treatment with Miro ${ }^{\text {WT }}$ or Miro $1^{\Delta \mathrm{EF}} 0 \mathrm{E}$ (Miro ${ }^{\mathrm{WT}}$ control: $n=11$ mitochondria, 3 slices; Miro $1^{\text {WT }}+4$-AP: $n=10$ mitochondria, 3 slices; Miro $1^{\Delta \mathrm{EF}}$ control and Miro ${ }^{\Delta \mathrm{EF}}+4-\mathrm{AP}: n=10$ mitochondria, 3 slices). $\boldsymbol{E}$, Mitochondrial length (morphology) pre-4-AP treatment and post-4-AP treatment with Miro $1^{\mathrm{WT}}$ or Miro ${ }^{\triangle \mathrm{EF}} \mathrm{OE}$ (Miro $1^{\mathrm{WT}}$ control and Miro ${ }^{\text {WT }}+4$-AP: $n=3$ cells, 3 slices; Miro ${ }^{\Delta \mathrm{EF}}$ control and Miro $1^{\Delta \mathrm{EF}}+4$-AP: $n=3$ cells, 3 slices). $\boldsymbol{F}$, Representative images of mitochondrial distribution in relation to VGLUT1-labeled synapses with Miro $1{ }^{\mathrm{WT}}$ and Miro ${ }^{\mathrm{AEF}} \mathrm{OE}$ before and following 4-AP treatment ( $5 \mathrm{~min}, 100 \mu \mathrm{M})$. Scale bars, $5 \mu \mathrm{m}$. G, Distance between mitochondria and their nearest VGLUT1-labeled synapse under basal conditions and with 4-AP

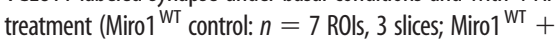
4-AP: $n=6$ ROls, 3 slices; Miro ${ }^{\Delta \mathrm{EF}}$ control: $n=7$ ROls, 3 slices; Miro ${ }^{\Delta \mathrm{EF}}+4$-AP: $n=7$ ROls, 3 slices). $\boldsymbol{H}$, Number of mitochondria and VGLUT1 puncta in analyzed ROIs (per $\mu \mathrm{m}$ ) with Miro $1{ }^{\text {WT }}$

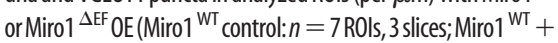
4-AP: $n=6$ ROls, 3 slices; Miro ${ }^{\Delta \mathrm{EF}}$ control: $n=7$ ROls, 3 slices; Miro ${ }^{\Delta \mathrm{EF}}+4$-AP: $n=7$ ROls, 3 slices). ${ }^{*} p<0.05,{ }^{* *} p<0.01$, ${ }^{* * *} p<0.001$. 
A
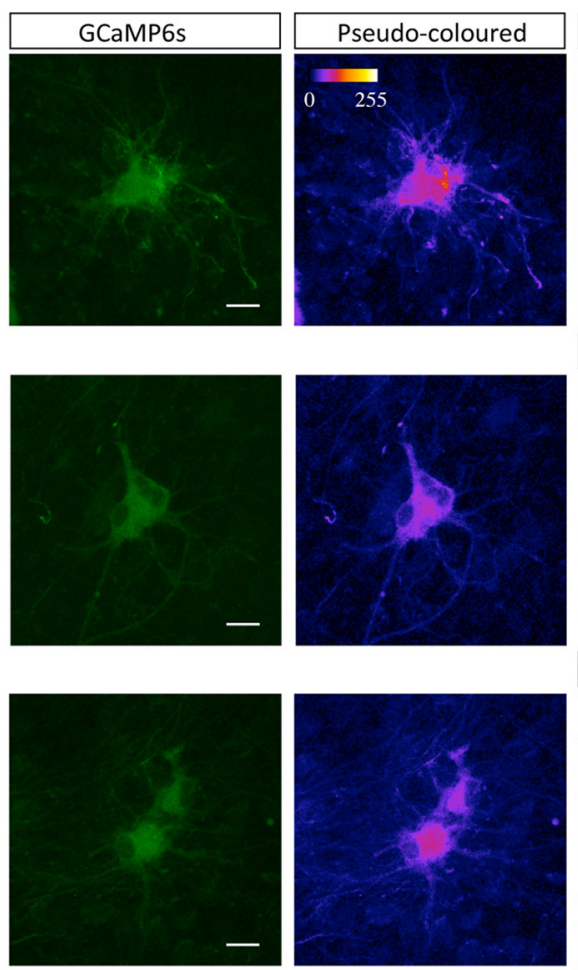

B

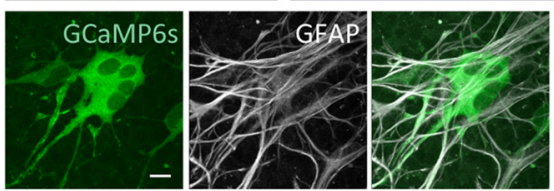

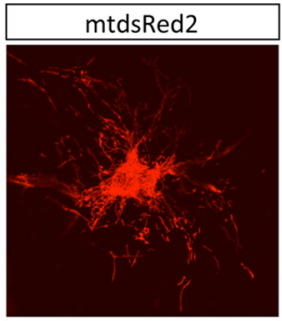
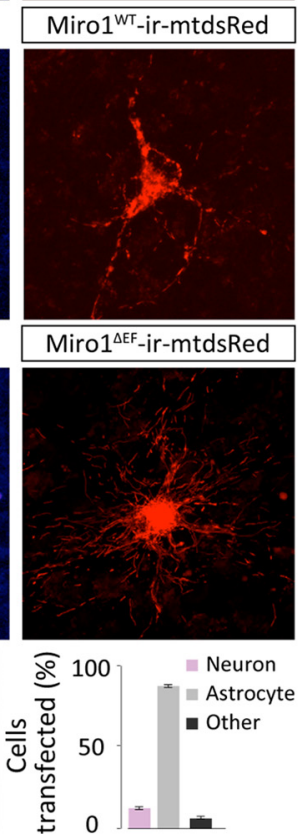

C

$\downarrow \mathrm{Ca}^{2+} \uparrow$ mitochondrial mobility

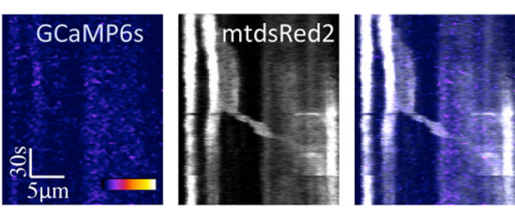

$\uparrow \mathrm{Ca}^{2+} \downarrow$ mitochondrial mobility

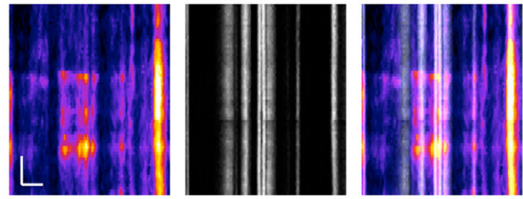

D $\quad$ Low $\mathrm{Ca}^{2+}$

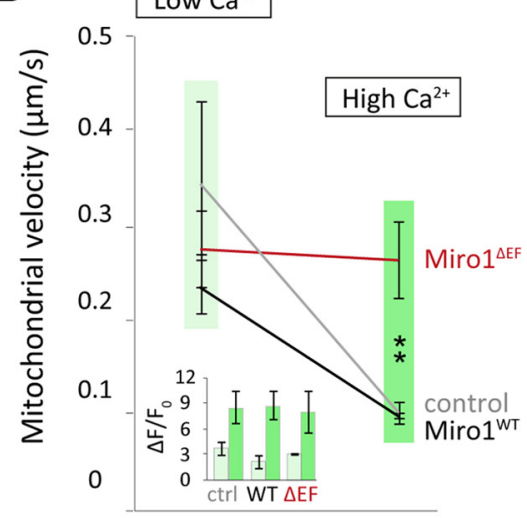

E Basal process $\mathrm{Ca}^{2+}$
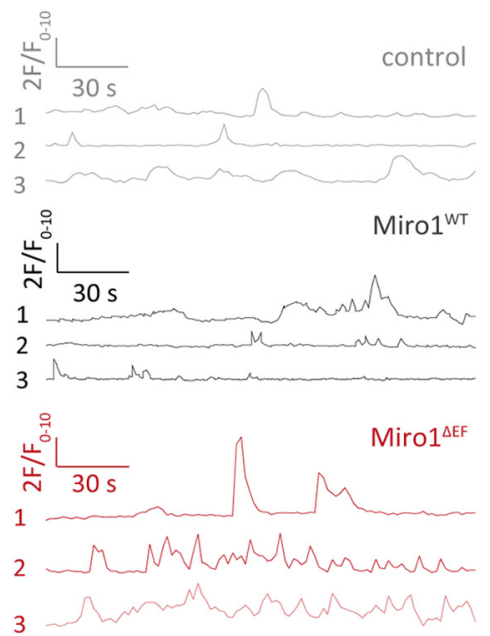

F Activity-driven process $\mathrm{Ca}^{2+}$

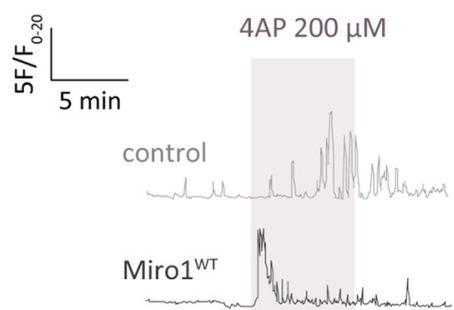

ATP $100 \mu \mathrm{M}$

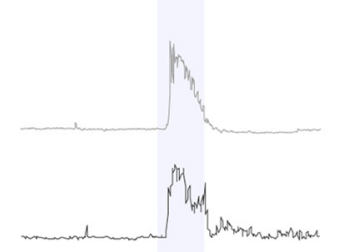

Miro1 $^{\Delta E}$

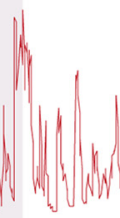

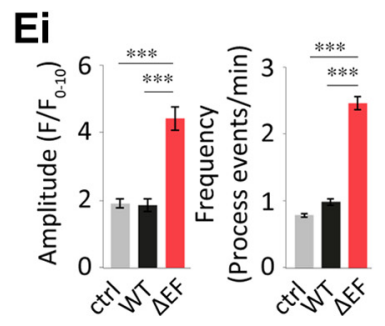
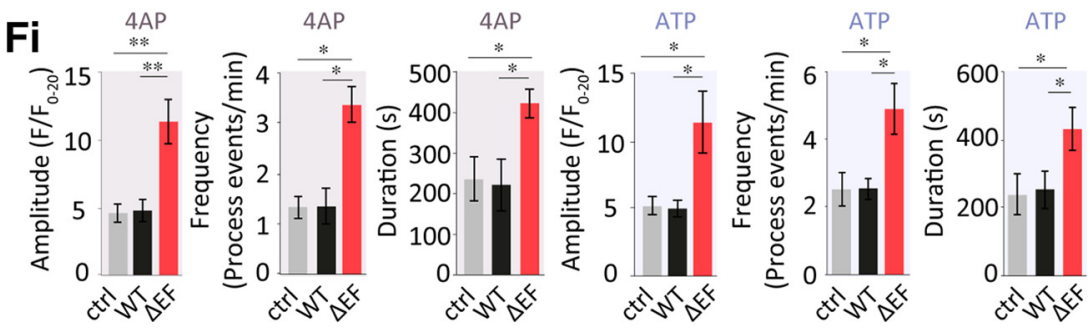

Figure 7. Mutant Miro1 (Miro1 ${ }^{\mathrm{DEF}}$ ) expression in slices disrupts intracellular astrocyte $\mathrm{Ca}^{2+}$-signaling. $\boldsymbol{A}$, Representative live confocal images of biolistically transfected hippocampal slices. Slices were shot $7 \mathrm{~d}$ after slicing with either mtdsRed2 (control) Miro ${ }^{\Delta \mathrm{EF}}$-ires-mtdsRed2 or Miro ${ }^{\mathrm{WT}}$-ires-mtdsRed2 along with GCaMP6s and imaged 2-3d later. B, GCaMP6s colocalizes more often with GFAP than MAP2. Bullets transfected astrocytes more readily than neurons; this can be seen also by identifying their unique $\mathrm{Ca}^{2+}$ dynamics (propagating $\mathrm{Ca}^{2+}$ waves: $n=51$ cells, 3 slices). C, Basal kymograph examples of mitochondrial trafficking in relation to intracellular $\mathrm{Ca}^{2+}$. Above example shows mitochondrial movement when intracellular $\mathrm{Ca}^{2+}$ is low (pseudo-colored blue-black; dim GCaMP6s). Immobile mitochondria frequently colocalize with areas of high intracellular $\mathrm{Ca}^{2+}$ (red-orange). High $\mathrm{Ca}^{2+}$ is reflected as a (Figure legend continues.) 
of mitochondria in relation to their nearest synapse decreased with Miro $1^{\mathrm{WT}} \mathrm{OE}$ following 4 -AP treatment ( 5 min, $100 \mu \mathrm{M}$; Fig. $6 G ; p=0.02)$ but not in slices with mutant Miro $1^{\Delta \mathrm{EF}} \mathrm{OE}$, where before treatment, the distribution was similar to untreated control conditions (Fig. $6 G ; p=0.8$ ). Importantly, no significant change was seen in synapse or mitochondrial number (per $\mu \mathrm{m}$; Fig. $6 H ; p=0.5$ and $p=0.8, p=0.1$, and $p=0.8$, respectively). Therefore, it appears that Mirol is important for regulating activity-driven mitochondrial stopping and their concomitant retention in astrocytic processes near synapses.

Mutant Miro1 (Miro1 ${ }^{\triangle E F}$ ) expression in slices disrupts intracellular astrocyte $\mathrm{Ca}^{2+}$-signaling

Finally, we asked whether the $\mathrm{Ca}^{2+}$-sensing EF-hands of Mirol are important for intracellular astrocyte $\mathrm{Ca}^{2+}$ regulation. To address this, we biolistically transfected astrocytes in rat hippocampal organotypic slices with either Mirol ${ }^{\text {WT }}$ or Mirol $^{\Delta \mathrm{EF}}$ (bicistronically expressing mtdsRed2) or mtdsRed2 alone (control) in addition to GCaMP6s (Fig. 7A). Specific transfection of astrocytes was confirmed by significant colocalization of the GCaMP6s signal with GFAP (Fig. 7B).

Using kymographs to overlay mitochondria and the corresponding $\mathrm{Ca}^{2+}$ signal, stationary mitochondria corresponded with regions of high intracellular $\mathrm{Ca}^{2+}$ (red-orange pseudocolored GCaMP6s), whereas mitochondrial movement occurred in regions of low $\mathrm{Ca}^{2+}$ (Fig. 7C, blue-black). Mitochondrial velocity was elevated in these regions of low $\mathrm{Ca}^{2+}(0.42 \pm 0.05$ $\mu \mathrm{m} / \mathrm{s}$; defined as $\left.\mathrm{F} / \mathrm{F}_{0}<5\right)$ and decreased significantly in regions of high $\mathrm{Ca}^{2+}\left(0.01 \pm 0.01 \mu \mathrm{m} / \mathrm{s} ; \mathrm{F} / \mathrm{F}_{0}>5\right.$; Fig. $\left.7 D ; p=0.0002\right)$. This further supports the idea that mitochondria stop at regions of elevated intracellular $\mathrm{Ca}^{2+}$. This halting of mitochondria at $\mathrm{Ca}^{2+}$ hot spots was disrupted with mutant Mirol ${ }^{\Delta \mathrm{EF}} \mathrm{OE}$ (Fig. $7 D ; p=0.8$ ) but not with Miro1 ${ }^{\mathrm{WT}}$ OE (Fig. $7 D ; p=0.002$ ), further supporting a role for intracellular $\mathrm{Ca}^{2+}$ regulating astrocyte mitochondrial trafficking via the EF-hand domains of Miro1 (Figs. 5, 6).

Interestingly, both the frequency and amplitude of basal $\mathrm{Ca}^{2+}$ transients was increased with Miro ${ }^{\Delta \mathrm{EF}} \mathrm{OE}$ in the processes of astrocytes compared with control conditions (mtdsRed2) and Miro ${ }^{\text {WT }}$ OE (Fig. 7Ei; amplitude, $p=5 \times 10^{-8}$ and $p=2 \times$ $10^{-5}$, respectively; frequency, $p=0.001$ and $p=4 \times 10^{-5}$, respectively). In addition, we observed significant increases in $\mathrm{Ca}^{2+}$ transients in the processes of astrocytes when stimulating neuronal activity with 4-AP (5 min, $200 \mu \mathrm{M})$ and with ATP (2 $\min , 100 \mu \mathrm{M}$; Fig. $7 F$ ). This rise in $\mathrm{Ca}^{2+}$ was even higher with

\section{$\leftarrow$}

(Figure legend continued.) change from dim to brighter GCaMP6s (as apposed to a persistently high signal). $\boldsymbol{D}$, Mitochondrial velocity in areas of low (light green) versus high (dark green) $\mathrm{Ca}^{2+}$. Inset, $\mathrm{F} / \mathrm{F}_{0}$ values reflecting regions of low (light green) and high $\mathrm{Ca}^{2+}$ (dark green; control: low $n=4$ cells, 3 slices; control high: $n=5$ cells, 3 slices; Miro ${ }^{\text {WT }}$ low: $n=6$ mitochondria, 4 slices; Miro ${ }^{\mathrm{WT}}$ high: $n=5$ mitochondria, 4 slices; Miro ${ }^{\Delta \mathrm{EF}}$ low: $n=5$ mitochondria, 4 slices; Miro ${ }^{\Delta \mathrm{EF}}$ high: $n=5$ mitochondria, 4 slices). Again, $\mathrm{Ca}^{2+}$ was only considered high if the GCaMP6s signal changed from dim to a brighter signal. $\boldsymbol{E}$, Basal process $\mathrm{Ca}^{2+}$ transients in controls (mtdsRed2; gray), with Miro $1{ }^{\mathrm{WT}}$ or Miro ${ }^{\Delta \mathrm{EF}}$ overexpression (OE), $\mathrm{F} / \mathrm{F}_{0}$ normalized to the first 5 frames $(10 \mathrm{~s})$. Ei, Quantification of basal $\mathrm{Ca}^{2+}$ transients; amplitude ( $/ / \mathrm{F}_{0}$, normalized to the first 5 frames; $10 \mathrm{~s}$ ) and frequency (process events $/ \mathrm{min}$; control: $n=27$ ROls, 7 slices; Miro $1^{\mathrm{WT}}: n=14 \mathrm{ROls}, 4$ slices; Miro ${ }^{\Delta \mathrm{EF}}: n=27 \mathrm{RO}$ ls, 7 slices). F, Process responses to 4-AP $(5 \mathrm{~min}, 200 \mu \mathrm{M})$ or ATP $(2 \mathrm{~min}, 100 \mu \mathrm{M})$ treatment, $\mathrm{F} / \mathrm{F}_{0}$ normalized to the first 10 frames (20 s). Fi, Quantification of amplitude $\left(F / F_{0}\right.$, normalized to the first 10 frames; $20 \mathrm{~s}$ ), frequency (process events/min) and response duration with 4AP and ATP treatment (control + 4-AP: $n=9$ ROls, 5 slices; Miro ${ }^{\mathrm{WT}}+4$-AP: $n=11$ ROls, 5 slices; Miro ${ }^{\mathrm{DEF}}+$ 4-AP: $n=10$ ROls, 4 slices; control + ATP: $n=10$ Rols, 9 slices; Miro ${ }^{\text {WT }}+$ ATP: $n=8$ ROls, 4 slices; Miro1 ${ }^{\Delta \mathrm{EF}}+$ ATP: $n=9$ R0ls, 7 slices). ${ }^{*} p<0.05,{ }^{* *} p<0.01,{ }^{* * *} p<0.001$.
Miro1 ${ }^{\Delta \mathrm{EF}}$ OE compared with control conditions (mtdsRed2) and Miro ${ }^{\text {WT }}$ OE. Compared with control conditions (mtdsRed2) and Mirol ${ }^{\text {WT }}$, OE of Miro ${ }^{\Delta \mathrm{EF}}$ significantly increased the response amplitude (Fig. $7 F i$; $p=0.002$ and $p=0.001$, respectively), frequency (Fig. 7Fi; $p=0.003$ and $p=0.002$, respectively) and duration to 4-AP (Figure Fi; $p=0.001$ and $p=1 \times 10^{-5}$, respectively). Compared with control conditions (mtdsRed2) and Mirol $^{\mathrm{WT}}$, Miro ${ }^{\Delta \mathrm{EF}}$ also significantly increased the response amplitude (Fig. $7 F i ; p=0.02$ and $p=0.02$, respectively), frequency (Fig. 7Fi; $p=0.02$ and $p=0.01$, respectively) and duration (Fig. 7Fi; $p=0.01$ and $p=0.02$, respectively) of $\mathrm{Ca}^{2+}$ rise within the astrocytes in response to ATP or neuronal stimulation. These results reveal that the spatial regulation of mitochondria by Mirol is important for intracellular $\mathrm{Ca}^{2+}$ signaling in astrocytes, which could have important consequences for their function, particularly in relation to gliotransmission.

\section{Discussion}

In this study, we have investigated the mechanisms that underlie activity-dependent trafficking and positioning of mitochondria in astrocytes. We show that astrocytes can sense neuronal activity and respond by raising their intracellular $\mathrm{Ca}^{2+}$, which alters their mitochondrial trafficking dynamics and positioning, dependent on the $\mathrm{Ca}^{2+}$ sensing EF-hand domains of Mirol. We show that this spatial regulation of astrocyte mitochondria by Mirol is important for astrocyte intracellular $\mathrm{Ca}^{2+}$ regulation, which could have important consequences for $\mathrm{Ca}^{2+}$ wave propagation and gliotransmission.

We investigated how mitochondrial dynamics in situ may differ in astrocytes compared with neurons. The number of mobile mitochondria is decreased in astrocytes, as well as the speed at which they are capable of moving, supporting previous observations (Jackson et al., 2014). However, we find that astrocyte mitochondria are still capable of covering the same distances as neuronal mitochondria. These differences in trafficking dynamics could be due to differences in the trafficking machinery used by astrocytes (Fiacco and McCarthy, 2004).

Synaptic activity can evoke feedback $\mathrm{Ca}^{2+}$ transients in astrocytes, which may alter their ability to release gliotransmitters (Perea and Araque, 2005; Serrano et al., 2006; Di Castro et al., 2011; Navarrete et al., 2013). Here we show that enhancing neuronal activity alters astrocyte mitochondrial trafficking dynamics and morphology. Mitochondria became shorter with a concomitant, transient reduction in movement when synaptic activity was stimulated. The activity-dependent reduction in mitochondrial size may facilitate mitochondrial stopping close to synapses within thinner astrocytic processes (Derouiche et al., 2015). Alterations in mitochondrial morphology can be accompanied by marked increases in reactive oxygen species and autophagy (Motori et al., 2013). However, in this study, recovery was seen after $24 \mathrm{~h}$, showing that these changes in morphology are reversible.

The response of mitochondrial trafficking to glutamate perfusion in our study involved activation of NMDARs and mGluRs but not AMPARs. A role for direct activation of astrocyte NMDARs in our work is mainly supported by experiments in pure astrocyte cultures where no neurons are present and which demonstrate that glutamate-dependent mitochondrial remodeling is blocked by NMDAR blockade. Indeed, expression of NMDARs has been described in rodent and human cultured astrocytes (Lee et al., 2010; Jimenez-Blasco et al., 2015). It should be noted, however, that it is hard to separate the inhibition of neuronal NMDARs and astrocytic NMDARs in our brain slice experiments where a primary effect of NMDAR activation will be to 
drive neuronal activation. Several studies have provided evidence for functional NMDARs in some spinal cord and cortical astrocytes, which is also supported by expression profiling studies of murine cortical astrocytes where the expression of selective NMDAR subunits was found (particularly NR2C; Verkhratsky and Kirchhoff, 2007; Cahoy et al., 2008; Palygin et al., 2011; Zhang et al., 2014). In contrast, there is little evidence for NMDAR responses in adult hippocampal astrocytes. However some studies have indicated that there may be an age-dependent expression of functional astrocyte NMDARs in juvenile rat hippocampal slices (Porter and McCarthy, 1995; Latour et al., 2001; Verkhratsky and Kirchhoff, 2007), an age similar to that of our organotypic slices and in hippocampal astrocytes in pathology (Krebs et al., 2003). Thus, NMDAR activation may provide a mechanism for the regulation of mitochondrial trafficking in hippocampal astrocytes during development and disease as well as in some cortical astrocytes in the adult. We also identified a partial role for mGluRs in our study, suggesting that $\mathrm{Ca}^{2+}$ release from internal stores could also act as a stop cue for mitochondrial trafficking in astrocytes. Thus, additional possible mechanisms for astrocyte $\mathrm{Ca}^{2+}$ rises downstream of neuronal activation may be the more prominent mechanisms for regulating astrocyte mitochondrial trafficking in the mature rodent hippocampus, including activation of mGluRs or Trp channels (Shigetomi et al., 2013; Verkhratsky et al., 2014) or activation of the reverse mode of the $\mathrm{Na}^{+} / \mathrm{Ca}^{2+}$ exchanger, which removes $\mathrm{Na}^{+}$that enters with glutamate uptake via glutamate transporters in exchange for $\mathrm{Ca}^{2+}$ (Goldman et al., 1994; Jackson et al., 2014).

Previously, it has been described that mitochondria localize within astrocytic processes in close proximity to glutamate transporters in an activity-dependent manner (Chaudhry et al., 1995; Genda et al., 2011; Jackson et al., 2014). However, it has not been investigated whether stimulating neuronal activity results in the retention of astrocyte mitochondria near synapses. Here we show that upon activation of glutamate receptors or pharmacological or electrical stimulation of neuronal activity, mitochondria in astrocytic processes position themselves near synapses within a fairly fast timescale (within $30 \mathrm{~s}$ ), where they were retained for tens of seconds, which is comparable to the timescale of activitydependent mitochondrial stopping and retention in neurons (Macaskill et al., 2009). Local recruitment of mitochondria may be required to ensure localized ATP production, in astrocytes, for glutamate metabolism and also to buffer the downstream entry of $\mathrm{Ca}^{2+}$ occurring in response to glutamate uptake (Goldman et al., 1994) in addition to the regulation of $\mathrm{Ca}^{2+}$ wave propagation and gliotransmission.

This study reveals several interesting features of the mechanisms that control mitochondrial trafficking and positioning along astrocytic processes involving Mirol. First, we provide new evidence of Mirol expression in rodent astrocytes and reveal that it is localized on mitochondria. Second, the $\mathrm{Ca}^{2+}$-binding EFhands of Mirol are not required for mitochondrial trafficking by motor proteins and basal mitochondrial trafficking, but our data does suggest that Miro1 regulates basal mitochondrial trafficking in astrocytes. It could be that increasing Mirol (Miro ${ }^{\text {WT }}$ or Miro ${ }^{\Delta \mathrm{EF}}$ ) increases the number of mitochondria coupled to motor proteins, allowing them to move more with increased speed. Third, the EF-hands of Mirol are essential for allowing mitochondrial stopping and remodeling in response to elevations in intracellular $\mathrm{Ca}^{2+}$. This reveals that the EF-hands of Mirol are important for regulating activity-driven mitochondrial stopping alongside changes in mitochondrial morphology in astrocytes.
Miro1 EF hand-dependent mitochondrial stopping appears to be important for the activity-driven retention of mitochondria in astrocyte processes close to synapses. This suggests that $\mathrm{Ca}^{2+}$ binding the EF-hands of Mirol is important for inducing mitochondrial stopping at predicted $\mathrm{Ca}^{2+}$ hot spots. Finally, Miro $1^{\triangle \mathrm{EF}} \mathrm{OE}$, in situ, alters the ability of astrocytes to regulate their intracellular $\mathrm{Ca}^{2+}$ levels. Miro1 ${ }^{\triangle \mathrm{EF}} \mathrm{OE}$ increased the frequency and amplitude of basal $\mathrm{Ca}^{2+}$ transients and increased the response to 4-AP and ATP. Here, we propose that astrocytes may be more vulnerable to $\mathrm{Ca}^{2+}$ overload when the $\mathrm{Ca}^{2+}$-sensing abilities of Mirol are disrupted. It would be interesting to test whether Mirol OE alters mitochondrial membrane potential and consequently their ability to buffer $\mathrm{Ca}^{2+}$. Disrupted intracellular $\mathrm{Ca}^{2+}$ regulation in astrocytes could have important consequences for their propagation of $\mathrm{Ca}^{2+}$ waves and suggests that the spatial regulation of mitochondria by Mirol plays an important role in regulating astrocyte signaling. Because the regulation of intracellular $\mathrm{Ca}^{2+}$ also has the potential to impact on gliotransmission, our study reveals another potential route for bidirectional communication between astrocytes and neurons. This could be linked to instances of pathology, as disrupted astrocyte $\mathrm{Ca}^{2+}$ dynamics due to altered mitochondrial function may impair neuronal function (Katayama et al., 1995; Danbolt, 2001; Shin et al., 2005; Voloboueva et al., 2007; Li et al., 2008; Bradford et al., 2009; Oliveira and Goncalves, 2009). Interestingly, basal $\mathrm{Ca}^{2+}$ transients are elevated in astrocytes in mice expressing mutant human A $\beta$ precursor protein (Kuchibhotla et al., 2009).

In summary, we demonstrate that Mirol regulates trafficking of mitochondria in the processes of astrocytes, as well as retention of mitochondria at sites that require energy production and $\mathrm{Ca}^{2+}$-buffering such as the tripartite synapse. Further work is required to confirm the exact interactions that mediate mitochondrial binding to their transport network in astrocytes, which could be actin or microtubule-dependent (Jackson et al., 2014). Miro has also recently been shown to be involved in the cascade that regulates mitophagy (Wang et al., 2011; Birsa et al., 2014; Tsai et al., 2014) and consequently, the regulation of mitophagy in astrocytes is an important mechanism that remains to be addressed (Stephen et al., 2014). Miro has also been implicated in disease (Iijima-Ando et al., 2012; Liu et al., 2012). Therefore, along with the data shown in this current study, this alludes to the possibility that astrocyte mitochondrial regulation by Miro is important, not only for astrocyte function, but also for neuronal signaling in the context of pathology.

\section{References}

Abbott NJ, Rönnbäck L, Hansson E (2006) Astrocyte-endothelial interactions at the blood-brain barrier. Nat Rev Neurosci 7:41-53. CrossRef Medline

Akerboom J, Chen TW, Wardill TJ, Tian L, Marvin JS, Mutlu S, Calderón NC, Esposti F, Borghuis BG, Sun XR, Gordus A, Orger MB, Portugues R, Engert F, Macklin JJ, Filosa A, Aggarwal A, Kerr RA, Takagi R, Kracun S, et al. (2012) Optimization of a GCaMP calcium indicator for neural activity imaging. J Neurosci 32:13819-13840. CrossRef Medline

Al Awabdh S, Miserey-Lenkei S, Bouceba T, Masson J, Kano F, MarinachPatrice C, Hamon M, Emerit MB, Darmon M (2012) A new vesicular scaffolding complex mediates the G-protein-coupled 5-HT1A receptor targeting to neuronal dendrites. J Neurosci 32:14227-14241. CrossRef Medline

Araque A, Carmignoto G, Haydon PG (2001) Dynamic signaling between astrocytes and neurons. Annu Rev Physiol 63:795-813. CrossRef Medline

Araque A, Parpura V, Sanzgiri RP, Haydon PG (1998) Glutamate-dependent astrocyte modulation of synaptic transmission between cultured hippocampal neurons. Eur J Neurosci 10:2129-2142. CrossRef Medline Attwell D, Buchan AM, Charpak S, Lauritzen M, Macvicar BA, Newman EA 
(2010) Glial and neuronal control of brain blood flow. Nature 468:232243. CrossRef Medline

Banker G, Goslin K (1998) Culturing nerve cells. Cambridge, MA: MIT.

Bartlett JS, Samulski RJ, McCown TJ (1998) Selective and rapid uptake of adeno-associated virus type 2 in brain. Hum Gene Ther 9:1181-1186. CrossRef Medline

Benediktsson AM, Schachtele SJ, Green SH, Dailey ME (2005) Ballistic labeling and dynamic imaging of astrocytes in organotypic hippocampal slice cultures. J Neurosci Methods 141:41-53. CrossRef Medline

Birsa N, Norkett R, Higgs N, Lopez-Domenech G, Kittler JT (2013) Mitochondrial trafficking in neurons and the role of the Miro family of GTPase proteins. Biochem Soc Trans 41:1525-1531. CrossRef Medline

Birsa N, Norkett R, Wauer T, Mevissen TE, Wu HC, Foltynie T, Bhatia K, Hirst WD, Komander D, Plun-Favreau H, Kittler JT (2014) Lysine 27 ubiquitination of the mitochondrial transport protein Miro is dependent on serine 65 of the Parkin ubiquitin ligase. J Biol Chem 289:14569-14582. CrossRef Medline

Bolte S, Cordelières FP (2006) A guided tour into subcellular colocalization analysis in light microscopy. J Microsc 224:213-232. CrossRef Medline

Bradford J, Shin JY, Roberts M, Wang CE, Li XJ, Li S (2009) Expression of mutant huntingtin in mouse brain astrocytes causes age-dependent neurological symptoms. Proc Natl Acad Sci U S A 106:22480-22485. CrossRef Medline

Cahoy JD, Emery B, Kaushal A, Foo LC, Zamanian JL, Christopherson KS, Xing Y, Lubischer JL, Krieg PA, Krupenko SA, Thompson WJ, Barres BA (2008) A transcriptome database for astrocytes, neurons, and oligodendrocytes: a new resource for understanding brain development and function. J Neurosci 28:264-278. CrossRef Medline

Carmignoto G (2000) Reciprocal communication systems between astrocytes and neurones. Prog Neurobiol 62:561-581. CrossRef Medline

Chaudhry FA, Lehre KP, van Lookeren Campagne M, Ottersen OP, Danbolt NC, Storm-Mathisen J (1995) Glutamate transporters in glial plasma membranes: highly differentiated localizations revealed by quantitative ultrastructural immunocytochemistry. Neuron 15:711-720. CrossRef Medline

Chen TW, Wardill TJ, Sun Y, Pulver SR, Renninger SL, Baohan A, Schreiter ER, Kerr RA, Orger MB, Jayaraman V, Looger LL, Svoboda K, Kim DS (2013) Ultrasensitive fluorescent proteins for imaging neuronal activity. Nature 499:295-300. CrossRef Medline

Danbolt NC (2001) Glutamate uptake. Prog Neurobiol 65:1-105. CrossRef Medline

D’Ascenzo M, Fellin T, Terunuma M, Revilla-Sanchez R, Meaney DF, Auberson YP, Moss SJ, Haydon PG (2007) mGluR5 stimulates gliotransmission in the nucleus accumbens. Proc Natl Acad Sci U S A 104:1995-2000. CrossRef Medline

Derouiche A, Haseleu J, Korf HW (2015) Fine astrocyte processes contain very small mitochondria: glial oxidative capability may fuel transmitter metabolism. Neurochem Res 1-12. CrossRef Medline

De Simoni A, Yu LM (2006) Preparation of organotypic hippocampal slice cultures: interface method. Nat Protoc 1:1439-1445. CrossRef Medline

Di Castro MA, Chuquet J, Liaudet N, Bhaukaurally K, Santello M, Bouvier D, Tiret P, Volterra A (2011) Local Ca2 + detection and modulation of synaptic release by astrocytes. Nat Neurosci 14:1276-1284. CrossRef Medline

Dienel GA, Cruz NF (2004) Nutrition during brain activation: does cell-tocell lactate shuttling contribute significantly to sweet and sour food for thought? Neurochem Int 45:321-351. CrossRef Medline

Dreosti E, Odermatt B, Dorostkar MM, Lagnado L (2009) A genetically encoded reporter of synaptic activity in vivo. Nat Methods 6:883-889. CrossRef Medline

Duale H, Kasparov S, Paton JF, Teschemacher AG (2005) Differences in transductional tropism of adenoviral and lentiviral vectors in the rat brainstem. Exp Physiol 90:71-78. CrossRef Medline

Edelstein A, Amodaj N, Hoover K, Vale R, Stuurman N (2010) Computer control of microscopes using microManager. Curr Protoc Mol Biol 14: Unit14.20. CrossRef Medline

Fiacco TA, McCarthy KD (2004) Intracellular astrocyte calcium waves in situ increase the frequency of spontaneous AMPA receptor currents in CA1 pyramidal neurons. J Neurosci 24:722-732. CrossRef Medline

Genda EN, Jackson JG, Sheldon AL, Locke SF, Greco TM, O’Donnell JC, Spruce LA, Xiao R, Guo W, Putt M, Seeholzer S, Ischiropoulos H, Robinson MB (2011) Co-compartmentalization of the astroglial glutamate transporter, GLT-1, with glycolytic enzymes and mitochondria. J Neurosci 31:18275-18288. CrossRef Medline

Goldman WF, Yarowsky PJ, Juhaszova M, Krueger BK, Blaustein MP (1994) Sodium/calcium exchange in rat cortical astrocytes. J Neurosci 14:58345843. Medline

Grosche J, Matyash V, Möller T, Verkhratsky A, Reichenbach A, Kettenmann H (1999) Microdomains for neuron-glia interaction: parallel fiber signaling to Bergmann glial cells. Nat Neurosci 2:139-143. CrossRef Medline

Gurskaya NG, Verkhusha VV, Shcheglov AS, Staroverov DB, Chepurnykh TV, Fradkov AF, Lukyanov S, Lukyanov KA (2006) Engineering of a monomeric green-to-red photoactivatable fluorescent protein induced by blue light. Nat Biotechnol 24:461-465. CrossRef Medline

Haydon PG (2001) GLIA: listening and talking to the synapse. Nat Rev Neurosci 2:185-193. CrossRef Medline

Haydon PG, Carmignoto G (2006) Astrocyte control of synaptic transmission and neurovascular coupling. Physiol Rev 86:1009-1031. CrossRef Medline

Iijima-Ando K, Sekiya M, Maruko-Otake A, Ohtake Y, Suzuki E, Lu B, Iijima KM (2012) Loss of axonal mitochondria promotes tau-mediated neurodegeneration and Alzheimer's disease-related tau phosphorylation via PAR-1. PLoS Genet 8:e1002918. CrossRef Medline

Jackson JG, O’Donnell JC, Takano H, Coulter DA, Robinson MB (2014) Neuronal activity and glutamate uptake decrease mitochondrial mobility in astrocytes and position mitochondria near glutamate transporters. J Neurosci 34:1613-1624. CrossRef Medline

Jimenez-Blasco D, Santofimia-Castaño P, Gonzalez A, Almeida A, Bolaños JP (2015) Astrocyte NMDA receptors' activity sustains neuronal survival through a Cdk5-Nrf2 pathway. Cell Death Differ 22:1877-1889. CrossRef Medline

Katayama Y, Maeda T, Koshinaga M, Kawamata T, Tsubokawa T (1995) Role of excitatory amino acid-mediated ionic fluxes in traumatic brain injury. Brain Pathol 5:427-435. CrossRef Medline

Kimelberg HK, Nedergaard M (2010) Functions of astrocytes and their potential as therapeutic targets. Neurotherapeutics 7:338-353. CrossRef Medline

Koyama R, Muramatsu R, Sasaki T, Kimura R, Ueyama C, Tamura M, Tamura N, Ichikawa J, Takahashi N, Usami A, Yamada MK, Matsuki N, Ikegaya Y (2007) A low-cost method for brain slice cultures. J Pharmacol Sci 104:191-194. CrossRef Medline

Krebs C, Fernandes HB, Sheldon C, Raymond LA, Baimbridge KG (2003) Functional NMDA receptor subtype $2 \mathrm{~B}$ is expressed in astrocytes after ischemia in vivo and anoxia in vitro. J Neurosci 23:3364-3372. Medline

Kremneva E, Kislin M, Kang X, Khiroug L (2013) Motility of astrocytic mitochondria is arrested by $\mathrm{Ca} 2+$-dependent interaction between mitochondria and actin filaments. Cell Calcium 53:85-93. CrossRef Medline

Kuchibhotla KV, Lattarulo CR, Hyman BT, Bacskai BJ (2009) Synchronous hyperactivity and intercellular calcium waves in astrocytes in Alzheimer mice. Science 323:1211-1215. CrossRef Medline

Latour I, Gee CE, Robitaille R, Lacaille JC (2001) Differential mechanisms of $\mathrm{Ca} 2+$ responses in glial cells evoked by exogenous and endogenous glutamate in rat hippocampus. Hippocampus 11:132-145. CrossRef Medline

Lee MC, Ting KK, Adams S, Brew BJ, Chung R, Guillemin GJ (2010) Characterisation of the expression of NMDA receptors in human astrocytes. PloS One 5:e14123. CrossRef Medline

Li L, Lundkvist A, Andersson D, Wilhelmsson U, Nagai N, Pardo AC, Nodin C, Ståhlberg A, Aprico K, Larsson K, Yabe T, Moons L, Fotheringham A, Davies I, Carmeliet P, Schwartz JP, Pekna M, Kubista M, Blomstrand F, Maragakis N, et al (2008) Protective role of reactive astrocytes in brain ischemia. J Cereb Blood Flow Metab 28:468-481. CrossRef Medline

Liu S, Sawada T, Lee S, Yu W, Silverio G, Alapatt P, Millan I, Shen A, Saxton W, Kanao T, Takahashi R, Hattori N, Imai Y, Lu B (2012) Parkinson's disease-associated kinase PINK1 regulates Miro protein level and axonal transport of mitochondria. PLoS Genet 8:e1002537. CrossRef Medline

Macaskill AF, Rinholm JE, Twelvetrees AE, Arancibia-Carcamo IL, Muir J, Fransson A, Aspenstrom P, Attwell D, Kittler JT (2009) Mirol is a calcium sensor for glutamate receptor-dependent localization of mitochondria at synapses. Neuron 61:541-555. CrossRef Medline

MacAskill AF, Atkin TA, Kittler JT (2010) Mitochondrial trafficking and the provision of energy and calcium buffering at excitatory synapses. Eur J Neurosci 32:231-240. CrossRef Medline 
Magrané J, Sahawneh MA, Przedborski S, Estévez ÁG, Manfredi G (2012) Mitochondrial dynamics and bioenergetic dysfunction is associated with synaptic alterations in mutant SOD1 motor neurons. J Neurosci 32:229242. CrossRef Medline

Malarkey EB, Parpura V (2008) Mechanisms of glutamate release from astrocytes. Neurochem Int 52:142-154. CrossRef Medline

Motori E, Puyal J, Toni N, Ghanem A, Angeloni C, Malaguti M, Cantelli-Forti G, Berninger B, Conzelmann KK, Götz M, Winklhofer KF, Hrelia S, Bergami M (2013) Inflammation-induced alteration of astrocyte mitochondrial dynamics requires autophagy for mitochondrial network maintenance. Cell Metab 18:844-859. CrossRef Medline

Muir J, Arancibia-Carcamo IL, MacAskill AF, Smith KR, Griffin LD, Kittler JT (2010) NMDA receptors regulate GABAA receptor lateral mobility and clustering at inhibitory synapses through serine 327 on the gamma2 subunit. Proc Natl Acad Sci U S A 107:16679-16684. CrossRef Medline

Nam HS, Benezra R (2009) High levels of Id1 expression define B1 type adult neural stem cells. Cell Stem Cell 5:515-526. CrossRef Medline

Navarrete M, Perea G, Maglio L, Pastor J, García de Sola R, Araque A (2013) Astrocyte calcium signal and gliotransmission in human brain tissue. Cereb Cortex 23:1240-1246. CrossRef Medline

Oliveira JM, Gonçalves J (2009) In situ mitochondrial Ca2 + buffering differences of intact neurons and astrocytes from cortex and striatum. J Biol Chem 284:5010-5020. CrossRef Medline

Palygin O, Lalo U, Pankratov Y (2011) Distinct pharmacological and functional properties of NMDA receptors in mouse cortical astrocytes. Br J Pharmacol 163:1755-1766. CrossRef Medline

Parri R, Crunelli V (2003) An astrocyte bridge from synapse to blood flow. Nat Neurosci 6:5-6. CrossRef Medline

Pathania M, Davenport EC, Muir J, Sheehan DF, López-Doménech G, Kittler JT (2014) The autism and schizophrenia associated gene CYFIP1 is critical for the maintenance of dendritic complexity and the stabilization of mature spines. Transl Psychiatry 25:e374. CrossRef Medline

Perea G, Araque A (2005) Properties of synaptically evoked astrocyte calcium signal reveal synaptic information processing by astrocytes. J Neurosci 25:2192-2203. CrossRef Medline

Perez-Alvarez A, Navarrete M, Covelo A, Martin ED, Araque A (2014) Structural and functional plasticity of astrocyte processes and dendritic spine interactions. J Neurosci 34:12738-12744. CrossRef Medline

Pham AH, McCaffery JM, Chan DC (2012) Mouse lines with photoactivatable mitochondria to study mitochondrial dynamics. Genesis 50 : 833-843. CrossRef Medline

Porter JT, McCarthy KD (1995) GFAP-positive hippocampal astrocytes in situ respond to glutamatergic neuroligands with increases in $[\mathrm{Ca} 2+] \mathrm{i}$. Glia 13:101-112. CrossRef Medline

Reyes RC, Brennan AM, Shen Y, Baldwin Y, Swanson RA (2012) Activation of neuronal NMDA receptors induces superoxide-mediated oxidative stress in neighboring neurons and astrocytes. J Neurosci 32:12973-12978. CrossRef Medline

Saotome M, Safiulina D, Szabadkai G, Das S, Fransson A, Aspenstrom P, Rizzuto R, Hajnóczky G (2008) Bidirectional Ca2+-dependent control of mitochondrial dynamics by the Miro GTPase. Proc Natl Acad Sci U S A 105:20728-20733. CrossRef Medline

Schwarz TL (2013) Mitochondrial trafficking in neurons. Cold Spring Harb Perspect Biol 5:a011304. CrossRef Medline

Serrano A, Haddjeri N, Lacaille JC, Robitaille R (2006) GABAergic network activation of glial cells underlies hippocampal heterosynaptic depression. J Neurosci 26:5370-5382. CrossRef Medline
Sheng ZH, Cai Q (2012) Mitochondrial transport in neurons: impact on synaptic homeostasis and neurodegeneration. Nat Rev Neurosci 13: 77-93. CrossRef Medline

Shigetomi E, Bushong EA, Haustein MD, Tong X, Jackson-Weaver O, Kracun S, Xu J, Sofroniew MV, Ellisman MH, Khakh BS (2013) Imaging calcium microdomains within entire astrocyte territories and endfeet with GCaMPs expressed using adeno-associated viruses. J Gen Physiol 141: 633-647. CrossRef Medline

Shin JY, Fang ZH, Yu ZX, Wang CE, Li SH, Li XJ (2005) Expression of mutant huntingtin in glial cells contributes to neuronal excitotoxicity. J Cell Biol 171:1001-1012. CrossRef Medline

Smith KR, Davenport EC, Wei J, Li X, Pathania M, Vaccaro V, Yan Z, Kittler JT (2014) GIT1 and betaPIX are essential for GABA(A) receptor synaptic stability and inhibitory neurotransmission. Cell Rep 9:298-310. CrossRef Medline

Sofroniew MV (2005) Reactive astrocytes in neural repair and protection. Neuroscientist 11:400-407. CrossRef Medline

Srinivasan R, Huang BS, Venugopal S, Johnston AD, Chai H, Zeng H, Golshani $\mathrm{P}$, Khakh $\mathrm{BS}(2015) \mathrm{Ca}(2+)$ signaling in astrocytes from Ip3r2 $\left(^{-1-}\right)$ mice in brain slices and during startle responses in vivo. Nat Neurosci 18:708-717. CrossRef Medline

Stephen TL, Gupta-Agarwal S, Kittler JT (2014) Mitochondrial dynamics in astrocytes. Biochem Soc Trans 42:1302-1310. CrossRef Medline

Tsai PI, Course MM, Lovas JR, Hsieh CH, Babic M, Zinsmaier KE, Wang X (2014) PINK1-mediated phosphorylation of Miro inhibits synaptic growth and protects dopaminergic neurons in Drosophila. Sci Rep 4:6962. CrossRef Medline

Twelvetrees AE, Yuen EY, Arancibia-Carcamo IL, MacAskill AF, Rostaing P, Lumb MJ, Humbert S, Triller A, Saudou F, Yan Z, Kittler JT (2010) Delivery of GABAARs to synapses is mediated by HAP1-KIF5 and disrupted by mutant huntingtin. Neuron 65:53-65. CrossRef Medline

Verkhratsky A, Kirchhoff F (2007) NMDA receptors in glia. Neuroscientist 13:28-37. CrossRef Medline

Verkhratsky A, Reyes RC, Parpura V (2014) TRP channels coordinate ion signalling in astroglia. Rev Physiol Biochem Pharmacol 166:1-22. CrossRef Medline

Voloboueva LA, Suh SW, Swanson RA, Giffard RG (2007) Inhibition of mitochondrial function in astrocytes: implications for neuroprotection. J Neurochem 102:1383-1394. CrossRef Medline

Volterra A, Liaudet N, Savtchouk I (2014) Astrocyte Ca $(2)(+)$ signalling: an unexpected complexity. Nat Rev Neurosci 15:327-335. CrossRef Medline

Wang X, Schwarz TL (2009) The mechanism of Ca2+-dependent regulation of kinesin-mediated mitochondrial motility. Cell 136:163-174. CrossRef Medline

Wang X, Winter D, Ashrafi G, Schlehe J, Wong YL, Selkoe D, Rice S, Steen J, LaVoie MJ, Schwarz TL (2011) PINK1 and Parkin target Miro for phosphorylation and degradation to arrest mitochondrial motility. Cell 147: 893-906. CrossRef Medline

Woods G, Zito K (2008) Preparation of gene gun bullets and biolistic transfection of neurons in slice culture. J Vis Exp 12:675. CrossRef Medline

Zhang Y, Chen K, Sloan SA, Bennett ML, Scholze AR, O’Keeffe S, Phatnani HP, Guarnieri P, Caneda C, Ruderisch N, Deng S, Liddelow SA, Zhang C, Daneman R, Maniatis T, Barres BA, Wu JQ (2014) An RNA-sequencing transcriptome and splicing database of glia, neurons, and vascular cells of the cerebral cortex. J Neurosci 34:11929-11947. CrossRef Medline 